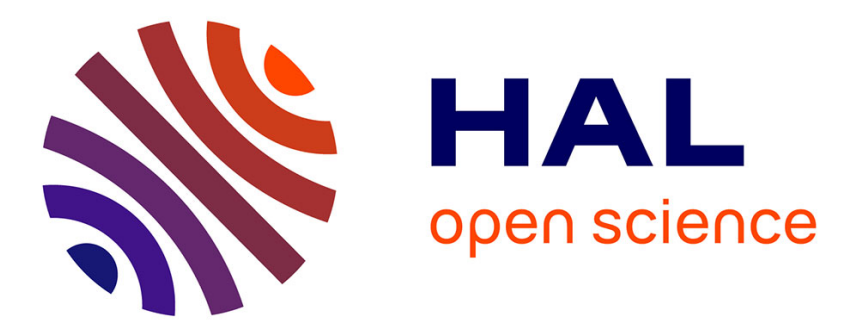

\title{
Nonlinear Soil Response of a Borehole Station Based on One-Dimensional Inversion during the 2005 Fukuoka Prefecture Western Offshore Earthquake
}

Florent de Martin, Hiroshi Kawase, Arézou Modaressi

\section{- To cite this version:}

Florent de Martin, Hiroshi Kawase, Arézou Modaressi. Nonlinear Soil Response of a Borehole Station Based on One-Dimensional Inversion during the 2005 Fukuoka Prefecture Western Offshore Earthquake. Bulletin of the Seismological Society of America, 2010, 100 (1), pp.151-171. $10.1785 / 0120090125$. hal-00560464

\section{HAL Id: hal-00560464 https: / hal-brgm.archives-ouvertes.fr/hal-00560464}

Submitted on 28 Jan 2011

HAL is a multi-disciplinary open access archive for the deposit and dissemination of scientific research documents, whether they are published or not. The documents may come from teaching and research institutions in France or abroad, or from public or private research centers.
L'archive ouverte pluridisciplinaire HAL, est destinée au dépôt et à la diffusion de documents scientifiques de niveau recherche, publiés ou non, émanant des établissements d'enseignement et de recherche français ou étrangers, des laboratoires publics ou privés. 


\title{
Nonlinear Soil Response of a Borehole Station Based on One-Dimensional Inversion during the 2005 Fukuoka Prefecture Western Offshore Earthquake
}

\author{
by Florent De Martin, Hiroshi Kawase, and Arézou Modaressi-Farahmand Razavi
}

\begin{abstract}
The objective of this article is to present the nonlinear response of a soft sedimentary site based on a one-dimensional inversion by a genetic algorithm of the shear-wave velocity structure and damping factors of a borehole soil column during the 2005 Fukuoka Prefecture Western Offshore earthquake. First, we confirm that, according to the source rupture mechanism, the major and minor axes in the horizontal plane at the borehole station are the transverse and radial directions, respectively. Then, in order to corroborate in the linear domain the $S$-wave transfer function of the borehole's logging, we perform time-dependent spectral ratios analyses on small aftershocks. Finally, we show qualitative evidence of nonlinearity during the mainshock associated with a significant shift toward low frequencies of several resonant modes, and we evaluate the degree of nonlinearity by inverting the shear-wave velocity structure and damping factors. Because of a directional effect present only in the major axis around $8 \mathrm{~Hz}$, which prevents the use of the conventional objective function that minimizes the integrated residuals between observed and theoretical ratios, we introduce a simple objective function that depends only on peaks' frequency and amplitude. The efficiency of the objective function and the robustness of the inversion are shown by performing eight independent inversions converging to very similar minima.
\end{abstract}

\section{Introduction}

Nonlinear behavior of soft soil observed during strong ground motions is now well established (e.g., Chin and Aki, 1991; Darragh and Shakal, 1991; Aki, 1993; Field et al., 1997; Su et al., 1998; Cultrera et al., 1999; Frankel et al., 2002; Aki, 2003; Bonilla et al., 2005), and the deployment of vertical arrays has contributed to detailed wave propagation analyses and the assessment for quantitative physical parameters such as shear-wave ( $S$-wave) velocity, pressurewave ( $P$-wave) velocity, and damping factors with respect to shear strain levels (e.g., Seed and Idriss, 1970a; Chang et al., 1991; Archuleta et al., 1992, 1993; Wen, 1994; Beresnev et al., 1995; Satoh et al., 1995; Zeghal et al., 1995; Ghayamghamain and Kawakami, 1996; Kawase et al., 1996; Aguirre and Irikura, 1997; Satoh et al., 1997, 2001; Bonilla et al., 2002; Pavlenko and Irikura, 2003; Kokusho, 2004; Pavlenko and Irikura, 2005, 2006; Assimaki and Steidl, 2007; ChávezGarcía and Raptakis, 2008; Kwok et al., 2008).

A natural approach to study borehole data is onedimensional (1D) modeling, which has been proven to be a good approximation for many cases (e.g., some of the aforementioned studies). Moreover, it has been shown during two blind-prediction experiments conducted by the International
Association of Seismology and Physics of the Earths Interior (IASPEI)/International Association for Earthquake Engineering (IAEE) Joint Working Group on Effects of Surface Geology on Strong Motions that the geological structure is more important than the model dimension (e.g., Cramer and Real, 1992; Mirodikawa, 1992). However, in recent years, 2D or 3D effects of basins have been found to be relevant for some strong ground motions (e.g., Bard et al., 1988; Kawase and Aki, 1989; Kawase and Sato, 1992; Graves, 1993; Frankel, 1994; Kawase and Matsushima, 1998). Those geometrical effects were observed essentially in the low-frequency range and would disappear in the high-frequency range because the shorter the wavelength, the more local the phenomenon. Unfortunately, short wavelengths are thought to be vulnerable to mutual interference of multiple reflection/refraction and to intrinsic or scattering attenuation, and, consequently, clear disappearance of 2D or 3D geometrical effects in the high-frequency range has not been reported yet.

In this study, we first confirm the major and minor axes of several stations surrounding the epicenter and then corroborate, at the borehole station, the 1D velocity structure in the linear elastic domain by computing time-dependent 
spectral ratios on the $S$-wave portion of small aftershocks. Possible geometrical effects, soil heterogeneity, and/or soilstructure interaction embedded within 1D spectral ratios are detected using $360^{\circ}$ spectral ratios.

Finally, conspicuous evidence of nonlinearity during the $S$-wave portion of the mainshock is shown by computing spectral ratios for which several resonant frequencies are shifted toward low frequencies. In order to quantify the degree of nonlinearity, we used a genetic algorithm (e.g., Goldberg, 1989; Yamanaka and Ishida, 1996) to invert the observed equivalent linear parameters (i.e., shear-wave velocity structure and damping factors) via the ThomsonHaskell propagator matrix method (e.g., Thomson, 1950; Haskell, 1953). Because of a directional effect present only in the major axis and clearly visible on $360^{\circ}$ spectral ratios around $8 \mathrm{~Hz}$, the conventional objective function, which minimizes the integrated residuals between observed and theoretical ratios cannot be used. We therefore introduce a simple objective function that depends only on the peaks' frequency and amplitude. To show the efficiency of the objective function and the robustness of the inversion, we perform eight independent inversions, which converge to very close solutions.

\section{Overview of Strong Ground Motions}

Fukuoka City is located on the northern part of Kyushu Island, southwestern Japan (Fig. 1, inset on the top left-hand side). A topographic map around the city is shown in Figure 1 (main panel). The 2005 Fukuoka Prefecture Western Offshore earthquake, with a Japanese Meteorological Agency (JMA) magnitude $M_{J}$ of $7.0\left(M_{\mathrm{w}} 6.6\right)$ and focal depth of $9.2 \mathrm{~km}$, occurred on 20 March 2005 off the northwestern coast of Kyushu Island along an unmapped fault at the northern extension of the well-known active fault, the Kego fault (e.g., Shibuya et al., 2009). Figure 2 shows the Kego fault and accelerograms at some stations surrounding the epicenter. Here we use K-NET (indicated by three letters + three digits) and KiK-net stations (indicated by three letters $+{ }^{\prime} H^{\prime}+$ two digits), as well as Fukuoka Prefecture's seismic intensity meter network (indicated by three letters $+{ }^{\prime} S^{\prime}+$ two digits). A rapid comparison between accelerograms at the K-NET station FKO006 and the other ones clearly shows that longer-period components are present at FKO006. This observation points out possible site effects caused by the existence of soft sediments within Fukuoka City.

In order to confirm the major and minor axes according to the source mechanism, we calculate the directional energy distribution given by equation 1 (e.g., Takizawa, 1982), which was successfully used to confirm the major axis of strong motion by Kawase and Aki (1990). First, the total power and cross spectra of the two orthogonal components $n$ (referring to north) and $e$ (referring to east) is calculated in the frequency range of interest:

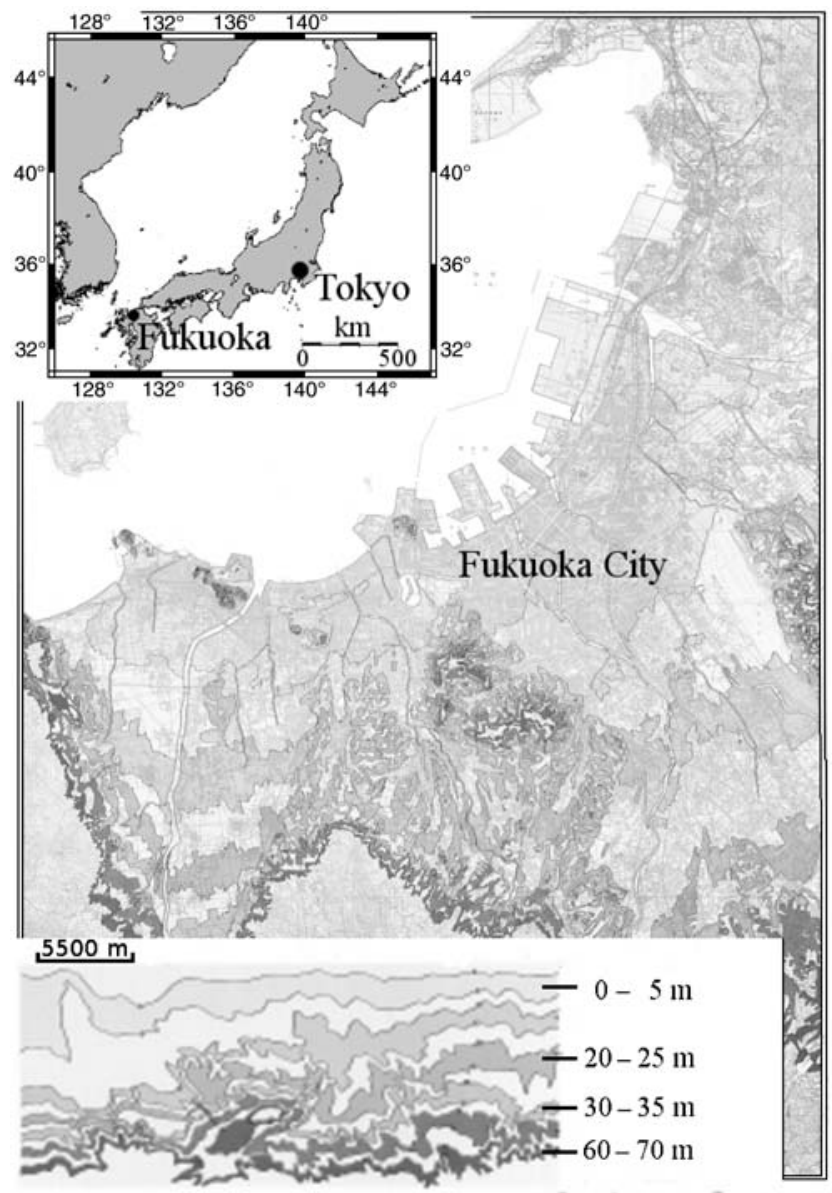

Figure 1. Inset on the top left-hand side: localization of Fukuoka City, northern Kyushu Island, Japan. Main panel: topographic map of Fukuoka City.

$$
[E]=\int_{\omega_{1}}^{\omega_{2}} \Re\left(\begin{array}{ll}
S_{n n}(\omega) & S_{n e}(\omega) \\
S_{e n}(\omega) & S_{e e}(\omega)
\end{array}\right) d \omega
$$

where $[E]$ is the matrix of energy of velocity power spectra, $\omega_{1}$ and $\omega_{2}$ are the lower and upper bounds of integration in the frequency domain, $\mathfrak{R}$ indicates the real part of a complex number, $S_{n n}(\omega)$ is a velocity power spectrum of the $n$ direction, and $S_{n e}(\omega)$ is a velocity cross power spectrum between the $n$ and $e$ direction, and so on. Then, the energy in the direction $\phi$, measured in a clockwise direction from the $n$-axis, can be obtained as

$$
E_{\phi}=\{\cos \phi, \sin \phi\}[E]\left\{\begin{array}{l}
\cos \phi \\
\sin \phi
\end{array}\right\}
$$

This energy distribution will be two elliptic lobes in line with the major axis if the ground motion is perfectly unidirectional, while it will become a single circle if the ground motion is not directional at all. The Fukuoka earthquake being a strike-slip crustal earthquake with a strike direction equal to $\mathrm{N} 122^{\circ} \mathrm{E}$, a dip angle of $89^{\circ}$, and a rake angle of $-11^{\circ}$ (e.g., Asano and Iwata, 2006), we can first plot the theoretical 


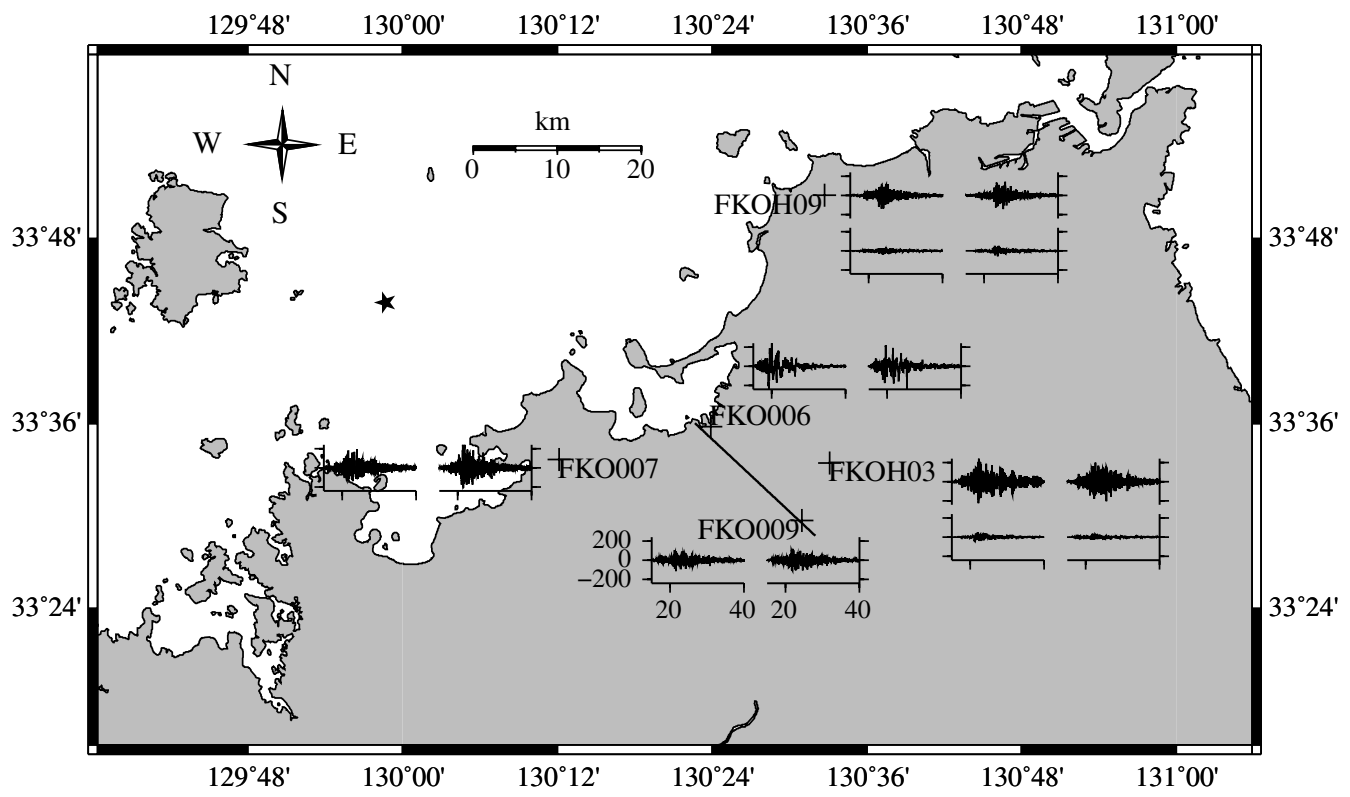

Figure 2. Location of the Kego fault (solid line at the southwestern side of the station FKO006) and accelerograms recorded at stations surrounding the epicenter (pointed out by a star) of the Fukuoka earthquake. Stations FKOxxx are stations from Kyoshin Network (K-NET) and stations FKOHxx or SAGHxx are stations from Kiban Kyoshin Network (KiK-net). For both K-NET and KiK-net stations, accelerograms on the left-hand side represent the north-south ground motion, and accelerograms on the right-hand side represent east-west ground motion. For KiK-net stations, accelerograms at the bottom are downhole records.

far-field radiation pattern of the now familiar double-couple mechanism in an infinite homogeneous medium to have in mind the predominant direction of motion. Figure 3 shows the $S$-wave radiation pattern and its $S H$ and $S V$ components. The fault plane (i.e., radial component) and the auxiliary plane (i.e., transverse component) are predominant planes for the $S$ wave. By decomposition of $S$ wave into $S H$ and $S V$ components, we see that the $S H$ component is predominant in the fault plane and in the auxiliary plane, whereas these planes are nodal lines for the $S V$ component.

Figures 4 and 5 show the energy distribution calculated in the horizontal plane for records observed at 22 stations. (a)
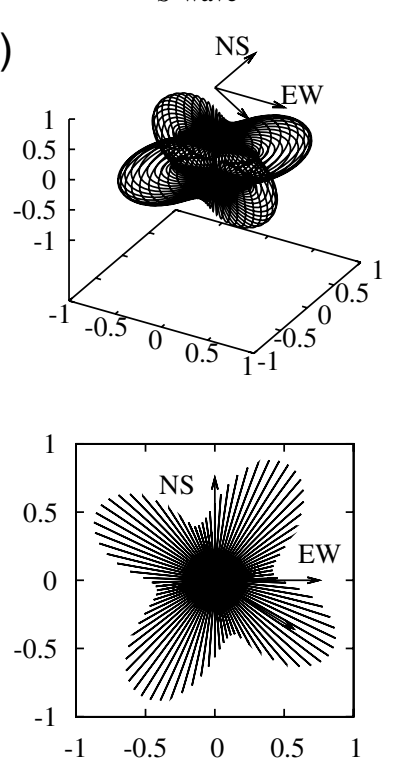

(b)
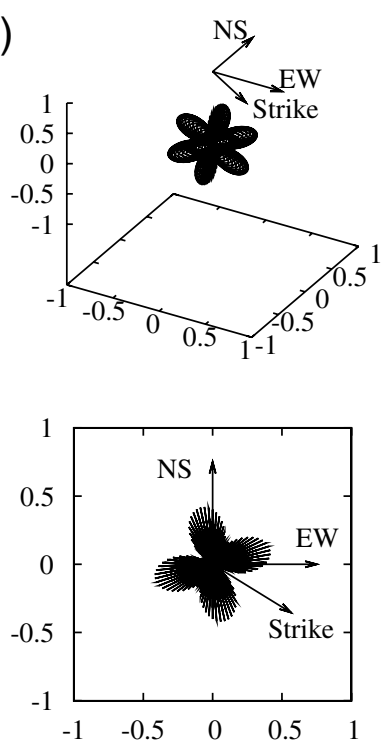

(c)
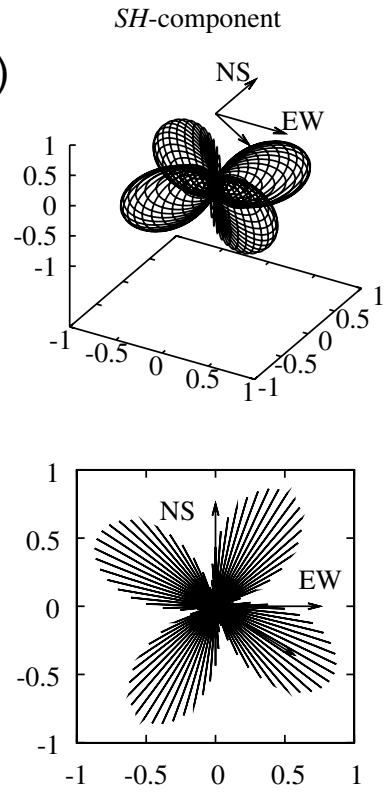

Figure 3. Theoretical far-field $S$-wave radiation pattern for a double-couple point source model in an infinite homogeneous medium oriented as follows: strike $=122^{\circ}$, dip $=89^{\circ}$ and rake $=-11^{\circ}$. North-south (NS), east-west (EW), and strike direction are indicated by arrows. Panels (a) show $S$-wave radiation patterns, and panels (b) and (c) expose $S V$ and $S H$ components of the $S$-wave, respectively. Top panels show a 3D view of the radiation patterns, and bottom panels show the radiation patterns mapped into the horizontal plane. 


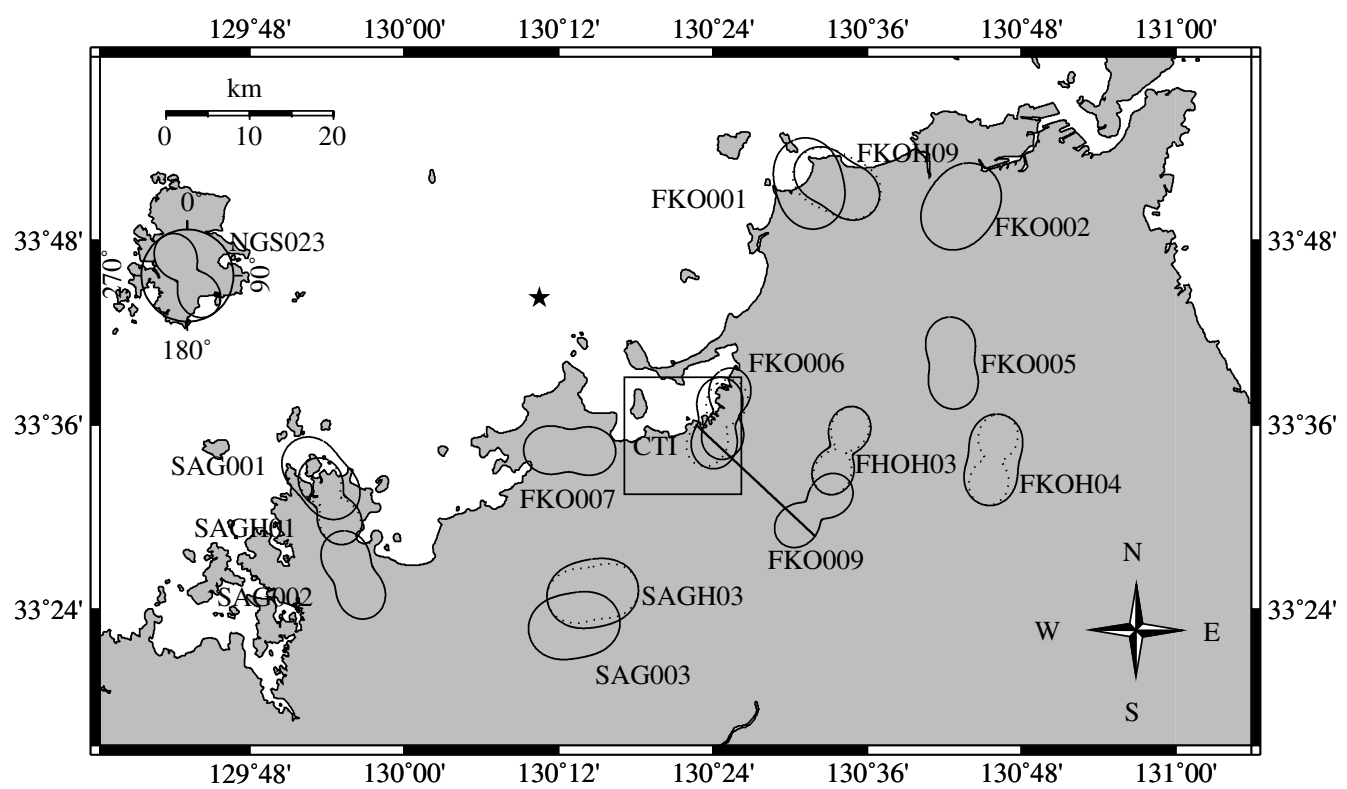

Figure 4. Energy distribution in the horizontal plane (north-south-east-west) for the records observed at stations within $60 \mathrm{~km}$ from the epicenter. The principal axis measured clockwise from the north (see station NGS023) has $\pm 180^{\circ}$ ambiguity. The energy distribution is calculated from velocity power spectra that are derived from north-south and east-west components of velocity seismograms (the entire record has been used to compute the power spectra). The frequency range used to integrate a power spectrum is $0.1-10 \mathrm{~Hz}$. Solid lines, energy distribution calculated at the free surface sensor; dashed lines, energy distribution calculated at the downhole sensor; solid straight line, location of the Kego fault; star, epicenter of the earthquake; rectangle denotes the area shown in Figure 5.

(It should be noted that, if necessary, these energy distributions have been corrected for the sensors' rotation for K-NET and KiK-net stations based on the information published by NIED). Depending on the station, observations show more or less a good agreement with the solution of the double-couple point source model. The energy distribution in the fault plane at the stations FKOS02, FKOS05, FKOS06 and FKO009 shows a good coherence because it exhibits a major axis

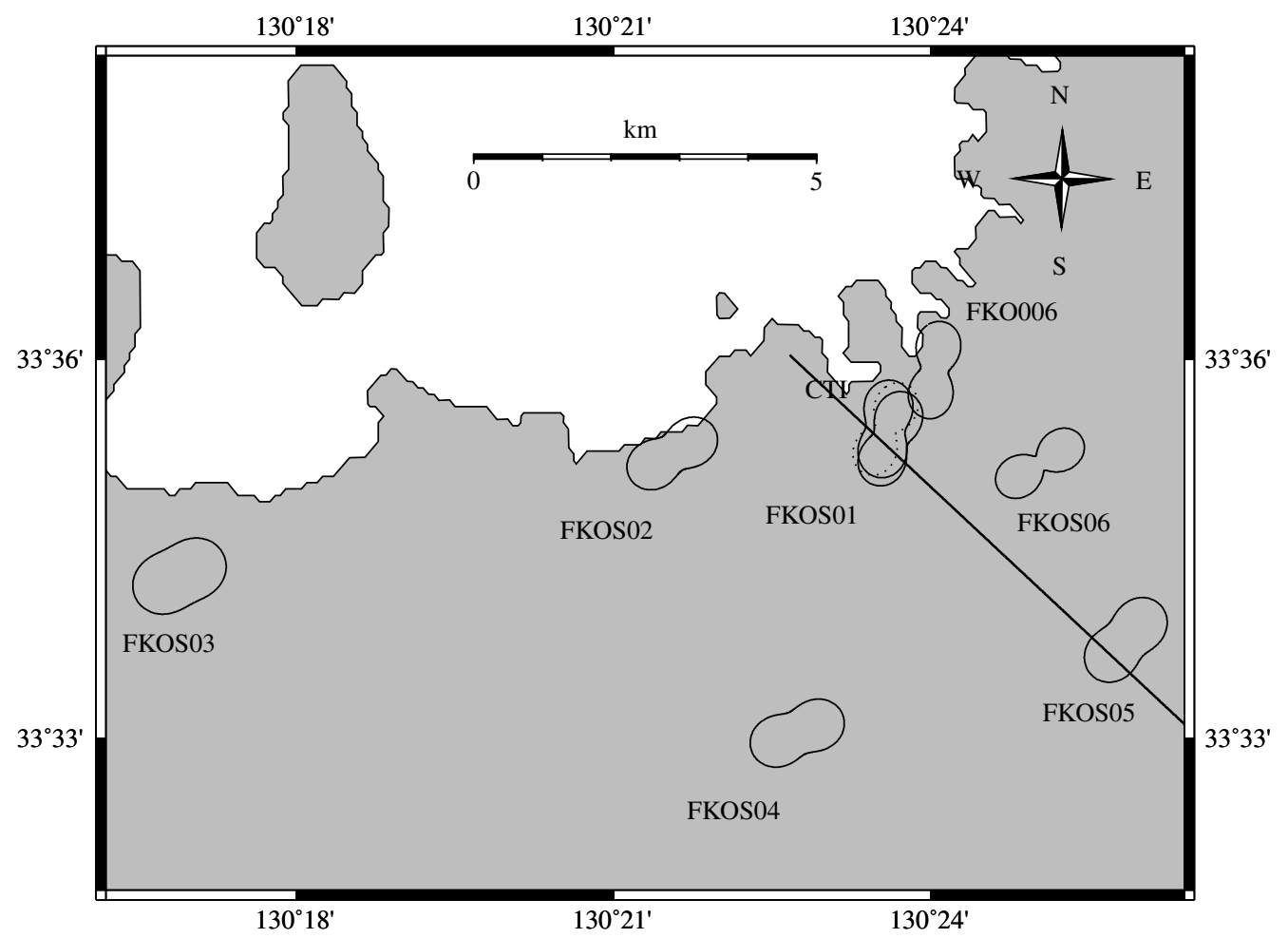

Figure 5. Zoom of the rectangle in Figure 4. Explanation are given in caption of Figure 4. Stations FKOSxx are stations from Fukuoka Prefecture's seismic intensity meter network. 
perpendicular to the fault plane (i.e., predominance of the $S H$ component). The same agreement can be seen for the auxiliary plane, where stations SAG001, SAGH01, and FKOH09 exhibit the same predominance. However, within Fukuoka City, the energy distribution of FKO006, FKOS01, and CTI is slightly rotated toward the north. This rotation could be due to basin geometrical effects and/or to trapped waves propagating along the fault gouge.

In the following section, we will describe the configuration of the borehole station and the data available at the borehole site.

\section{The Borehole Station: Configuration and Data}

The borehole station used in this study is the CTI Engineering Co., Ltd., borehole station located within Fukuoka's basin in a zone where the sediment thickness is the largest $(\approx 62 \mathrm{~m})$. North-south and east-west geologic cross sections realized $100 \mathrm{~m}$ from the borehole are shown in Figure 6. On the western and southern side of the borehole, the abrupt variation of the sediment-bedrock interface is due to the activity of the Kego fault indicated by crosses. The bedrock's depth increases from $10 \mathrm{~m}$ to $60 \mathrm{~m}$ in approximately $300 \mathrm{~m}$.

The borehole station is composed of two sensors, with a sample frequency of $100 \mathrm{~Hz}$, located below CTI Engineering's seven-story base-isolated building, as shown in the schematic view of Figure 7. One sensor is placed in the basement of the building, and the other one is embedded inside the bedrock $67 \mathrm{~m}$ below the free surface. Hereafter, we call these sensors: basement sensor and downhole sensor, respectively. because the fundamental frequency of such a baseisolated building is around $0.3-0.4 \mathrm{~Hz}$ and because the fundamental frequency of the CTI soil column is $1.4 \mathrm{~Hz}$ (see section Surface-to-Downhole Spectral Ratios during Aftershocks), we neglect soil-structure interaction and the basement sensor is considered as a free surface sensor. A third sensor located at the seventh story of the building has not been used for this study. Previous studies related to the CTI

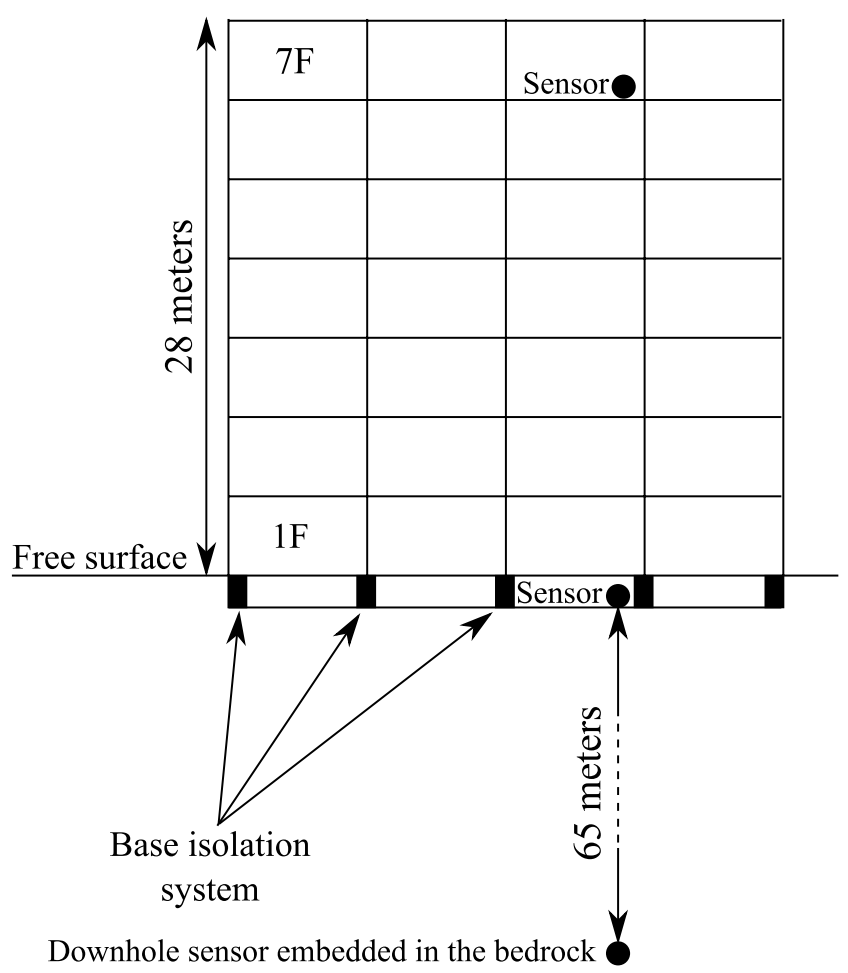

Figure 7. Schematic representation of the system \{base-isolated building + borehole station $\}$ at the CTI Engineering site. Sensors are represented by circles.

Engineering site are the following: Mazda et al. (2005); Satoh and Kawase (2005); Kawase et al. (2006).

The geology of the 1D soil column consists of an alternation of sand and clay overlying a thick layer of gravel and bedrock. The top $15 \mathrm{~m}$ mainly consists of sand in which the $S$-wave velocity increases from $150 \mathrm{~m} / \mathrm{sec}$ to $250 \mathrm{~m} / \mathrm{sec}$ and Standard Penetration Test (SPT) $N$-values ranges between 2 and 34. Then follows an alternation of clay and sand in which $S$-wave velocity ranges between $282 \mathrm{~m} / \mathrm{sec}$ and $411 \mathrm{~m} / \mathrm{sec}$ and SPT $N$-values between 10 and the upper limit of 50. Below those layers, a thick layer of $11 \mathrm{~m}$ of gravel, in

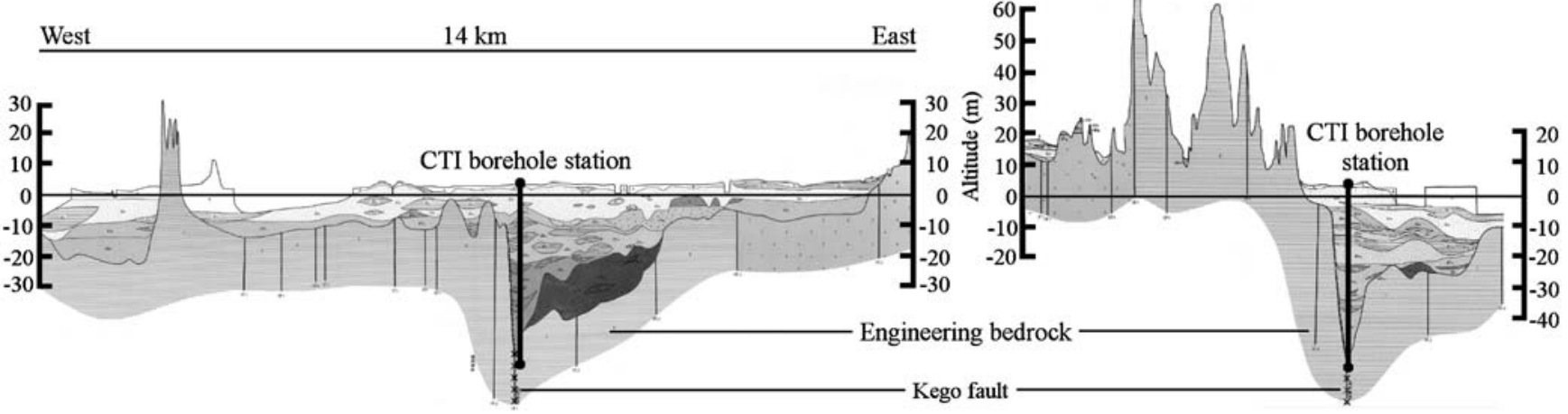

Figure 6. North-south and east-west geologic cross sections located some hundred meters from the CTI borehole station. The vertical axis has been exaggerated. Solid line, borehole station; points along solid line, sensors; crosses, the Kego fault. 
which $S$-wave velocity is approximately $500 \mathrm{~m} / \mathrm{sec}$, overlays the engineering bedrock of mudstone, which dates from the pre-Tertiary period of Cenozoic era and in which the $S$-wave velocity is approximately $500 \mathrm{~m} / \mathrm{sec}$.

Characteristics of records of the mainshock and aftershocks provided by CTI Engineering are shown in Table 1. EQ01 refers to the mainshock, and EQ02 to EQ25 refer to aftershocks. Figure 8 displays the location of their epicenters around the CTI station. A clear alignment of the events with the Kego fault can be seen. Table 2 shows the peak ground acceleration (PGA) of the mainshock and aftershocks in major and minor axes.

In the following section, we will describe surface-todownhole spectral ratios performed in the major and minor axes associated with transverse and radial components, respectively.

\section{Surface-to-Downhole Spectral Ratios during Aftershocks}

The original PS logging being very detailed (i.e., 12 layers with 39 measurements of $S$-wave and $P$-wave velocity), we have simplified the soil column by taking the average of velocities within each layer in order to facilitate the inversion. The simplified linear elastic soil properties and SPT $N$-values are presented in Table 3 . The original and simplified velocity profile for $S$ wave and $P$ wave are shown in Figure 9a,b, respectively. Their 1D spectral ratio computed for a vertically incident $S$ wave are shown in Figure 9c.
Figure 9c shows that the simplification has no influence on the first six resonant frequencies and has only a small influence on higher frequencies. The fundamental frequency of the soil column is found to be $1.4 \mathrm{~Hz}$.

In order to detect resonant frequencies of the soil column in the linear elastic domain, we use aftershocks for which the PGA at the basement sensor does not exceed $40 \mathrm{Gal}$ and perform spectral ratios analyses either by choosing a fixed $S$-wave portion selected by eye or by using a time-dependent (moving window) spectral ratio around the $S$-wave portion.

Figure 10 shows spectral ratios for which the $S$-wave portion has been chosen by eye. The length of the $S$ wave has been tuned for each earthquake and is generally larger than $1 \mathrm{sec}$ and smaller than $5 \mathrm{sec}$. A cosine shape of $25 \%$ at both ends of the $S$ wave has been used to smoothly set the data to zero at the boundaries of the window. We can see that observed and theoretical fundamental frequencies in the transverse direction show a good agreement whereas the theory tends to underestimate the fundamental frequency in the radial direction. In order to have a full vision of the directional dependence of spectral ratios, we compute $360^{\circ}$ spectral ratios using the aftershocks; $360^{\circ}$ spectral ratios are spectral ratios computed by rotating simultaneously in the horizontal plane basement and downhole records from the north and plotting them as a mapped view with respect to their azimuth by using a color code to represent their amplitude. By computing $360^{\circ}$ spectral ratios on all aftershocks, we find for several spectral ratios that the fundamental

Table 1

List of Earthquakes with Parameters Determined by Japan Meteorological Agency

\begin{tabular}{cccccc}
\hline Aftershock Numbers & Date/Time & Lat./Lon. & Focal depth $(\mathrm{km})$ & $\mathrm{M}_{J}{ }^{*}$ & Hypocentral distance from CTI $(\mathrm{km})$ \\
\hline EQ01 & $2005.03 .20 / 10 \mathrm{~h} 53$ & $33.74 / 130.18$ & 9 & 7.0 & 27.5 \\
EQ02 & $2005.04 .20 / 06 \mathrm{~h} 11$ & $33.68 / 130.29$ & 14 & 5.8 & 23.6 \\
EQ03 & $2005.04 .21 / 07 \mathrm{~h} 32$ & $33.77 / 130.11$ & 12 & 3.8 & 35.1 \\
EQ04 & $2005.04 .24 / 11 \mathrm{~h} 25$ & $33.65 / 130.32$ & 11 & 3.1 & 14.2 \\
EQ05 & $2005.04 .25 / 04 \mathrm{~h} 37$ & - & - & - & - \\
EQ06 & $2005.04 .28 / 03 \mathrm{~h} 43$ & $33.67 / 130.30$ & 13 & 3.8 & 17.7 \\
EQ07 & $2005.05 .02 / 01 \mathrm{~h} 24$ & $33.67 / 130.32$ & 11 & 5.0 & 15.5 \\
EQ08 & $2005.05 .03 / 01 \mathrm{~h} 29$ & $33.61 / 130.41$ & 8 & 3.1 & 8.5 \\
EQ09 & $2005.05 .10 / 11 \mathrm{~h} 53$ & - & - & - & - \\
EQ10 & $2005.05 .13 / 18 \mathrm{~h} 52$ & $33.75 / 130.12$ & 13 & 3.9 & - \\
EQ11 & $2005.05 .29 / 00 \mathrm{~h} 58$ & - & - & - & 12.0 \\
EQ12 & $2005.05 .30 / 08 \mathrm{~h} 52$ & $33.67 / 130.38$ & 8 & 3.0 & 37.2 \\
EQ13 & $2005.06 .03 / 04 \mathrm{~h} 23$ & $33.77 / 130.09$ & 15 & 4.1 & 33.6 \\
EQ14 & $2005.06 .26 / 19 \mathrm{~h} 55$ & $33.70 / 130.25$ & 10 & 3.4 & - \\
EQ15 & $2005.07 .05 / 05 \mathrm{~h} 10$ & $33.74 / 130.12$ & 15 & 4.2 & 19.9 \\
EQ16 & $2005.05 .30 / 14 \mathrm{~h} 55$ & - & - & - & 19.2 \\
EQ17 & $2005.08 .03 / 12 \mathrm{~h} 45$ & $33.70 / 130.24$ & 6 & 3.5 & 36.0 \\
EQ18 & $2005.08 .09 / 04 \mathrm{~h} 13$ & $33.69 / 130.29$ & 12 & 3.3 & 22.7 \\
EQ19 & $2005.09 .12 / 20 \mathrm{~h} 19$ & $33.78 / 130.10$ & 12 & 4.1 & 30.0 \\
EQ20 & $2005.09 .13 / 17 \mathrm{~h} 01$ & $33.70 / 130.27$ & 15 & 3.5 & 3.8 \\
EQ21 & $2005.11 .12 / 05 \mathrm{~h} 41$ & $33.74 / 130.18$ & 15 & 3.7 & 35.5 \\
EQ22 & $2005.12 .09 / 02 \mathrm{~h} 15$ & $33.68 / 130.31$ & 15 & 3.6 & - \\
EQ23 & $2006.01 .31 / 00 \mathrm{~h} 19$ & $33.77 / 130.12$ & 14 & 3.8 & \\
EQ24 & $2006.04 .28 / 00 \mathrm{~h} 19$ & $33.77 / 130.11$ & 13 & 3.8 & -8 \\
EQ25 & $2006.08 .25 / 15 \mathrm{~h} 09$ & - & - & - & \\
\hline
\end{tabular}

$* M_{J}$, Japan Meteorological Agency magnitude; —, values are unknown. 


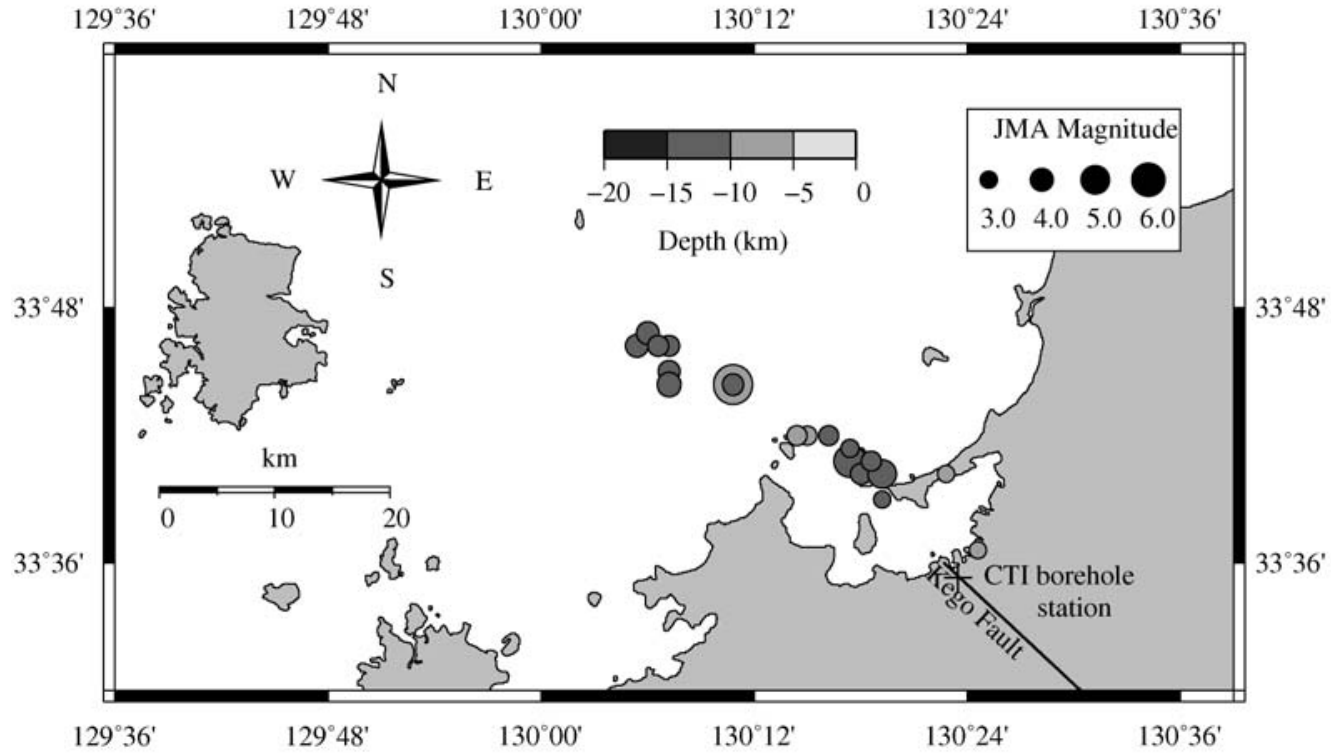

Figure 8. Epicenters of the events used in this study.

frequency forms a spiral instead of forming a circle in accordance with 1D theory as shown in Figure 11. Because of the particular location of the borehole station, this phenomenon could be due either to soil heterogeneity, geometrical effects, and/or soil-structure interaction. As for the second resonant

Table 2

PGA in Major and Minor Axes Recorded during Mainshock and Aftershocks

\begin{tabular}{|c|c|c|c|c|}
\hline \multirow[b]{3}{*}{ Aftershock Number } & \multicolumn{4}{|c|}{ PGA (Gal) } \\
\hline & \multicolumn{2}{|c|}{ Major Axis } & \multicolumn{2}{|c|}{ Minor Axis } \\
\hline & Free Surface & Downhole & Free Surface & Downhole \\
\hline EQ01 & 362.0 & 164.3 & 419.7 & 151.7 \\
\hline EQ02 & 278.8 & 97.6 & 267.3 & 108.9 \\
\hline EQ03 & 3.1 & 1.1 & 4.9 & 1.4 \\
\hline EQ04 & 3.5 & 1.3 & 4.6 & 1.8 \\
\hline EQ05 & 6.0 & 1.9 & 8.5 & 2.3 \\
\hline EQ06 & 8.1 & 2.4 & 11.2 & 3.2 \\
\hline EQ07 & 83.9 & 23.8 & 152.2 & 37.8 \\
\hline EQ08 & 15.0 & 4.4 & 28.0 & 9.8 \\
\hline EQ09 & 4.6 & 1.9 & 8.3 & 2.8 \\
\hline EQ10 & 4.8 & 1.6 & 7.7 & 2.1 \\
\hline EQ11 & 3.7 & 1.2 & 5.2 & 1.3 \\
\hline EQ12 & 5.6 & 2.1 & 10.6 & 2.7 \\
\hline EQ13 & 6.0 & 2.4 & 10.4 & 2.6 \\
\hline EQ14 & 3.0 & 0.8 & 3.3 & 1.2 \\
\hline EQ15 & 21.7 & 8.9 & 35.7 & 8.1 \\
\hline EQ16 & 3.9 & 1.8 & 5.9 & 2.0 \\
\hline EQ17 & 6.1 & 1.8 & 9.7 & 3.2 \\
\hline EQ18 & 4.4 & 1.4 & 7.7 & 2.2 \\
\hline EQ19 & 7.5 & 2.2 & 10.4 & 3.1 \\
\hline EQ20 & 5.8 & 2.1 & 7.8 & 2.8 \\
\hline EQ21 & 3.7 & 1.5 & 6.2 & 1.3 \\
\hline EQ22 & 10.6 & 2.0 & 8.9 & 3.2 \\
\hline EQ23 & 9.0 & 3.4 & 17.0 & 4.1 \\
\hline EQ24 & 4.7 & 1.8 & 7.0 & 3.2 \\
\hline EQ25 & 4.7 & 1.6 & 7.2 & 1.9 \\
\hline
\end{tabular}

frequency, even if its position fluctuates in the observations for both directions, the theoretical peak seems to correspond well to the observed ones. The precise position of higher frequencies are hardly seen in the observations.

In order to find the best location of spectral ratio time windows to observe resonant frequencies, we also perform time-dependent spectral ratios analyses around the $S$-wave portion of aftershocks. A time-dependent spectral ratio is the ratio of the short-time Fourier transform of the basement record with respect to the downhole record, the short-time Fourier transform being defined as

$$
\operatorname{STFT}\{x(t)\} \equiv x(\tau, \omega)=\int_{-\infty}^{\infty} x(t) w(t-\tau) e^{+i \omega t} d t
$$

where $w(t-\tau)$ is a window function and $x(t)$ is the signal to be transformed. $x(\tau, \omega)$ is essentially the Fourier transform of $x(t) w(t-\tau)$, a complex function representing the phase and magnitude of the signal over time and frequency. Time and frequency being conjugate variables and given a signal containing some event, one cannot assign simultaneously an exact time and frequency response scale to that event; consequently, the more precisely one variable is known, the less precisely the other is known. Because we focus in this study on the fundamental frequency of the soil column and its higher modes, the sliding window used to isolate a portion of the waveform is a Tukey window (often called cosinetapered) of ratio 1 (i.e., no flat portion is present in the Tukey window) and length $2.56 \mathrm{sec}$; that is to say, $85 \%$ of its length contains approximately three fundamental periods. Sliding windows are overlapped by $96 \%$ which corresponds to 0.1 sec. Moreover, we do not apply a time shift between basement and downhole sensors to account for the travel time. 
Table 3

Simplified Soil Profile Based on the Density and PS Logging Provided by CTI Engineering

\begin{tabular}{|c|c|c|c|c|c|c|c|}
\hline Layer Number & Depth (m) & Thickness (m) & $S$-Wave Velocity $(\mathrm{m} / \mathrm{sec})$ & $P$-Wave Velocity $(\mathrm{m} / \mathrm{sec})$ & Density $\left(\mathrm{g} / \mathrm{cm}^{3}\right)$ & Mean of $N$-Values & Soil Classification \\
\hline 1 & 5.5 & 3.5 & 152.1 & 1194.3 & 1.80 & 10.25 & sand \\
\hline 2 & 8.5 & 3.0 & 165.2 & 1209.7 & 1.80 & 2.67 & sand with clay \\
\hline 3 & 16.5 & 8.0 & 248.7 & 1706.8 & 1.80 & 23.12 & sand \\
\hline 4 & 25.5 & 9.0 & 229.6 & 1587.6 & 1.70 & 11.56 & clay \\
\hline 5 & 33.0 & 7.5 & 351.3 & 1730.0 & 1.90 & 30.00 & sand \\
\hline 6 & 36.0 & 3.0 & 289.0 & 1712.0 & 1.75 & 25.00 & clay \\
\hline 7 & 40.0 & 4.0 & 324.7 & 1744.9 & 1.90 & 49.00 & sand \\
\hline 8 & 43.0 & 3.0 & 282.0 & 1765.2 & 1.75 & 17.00 & clay \\
\hline 9 & 47.0 & 4.0 & 411.5 & 1785.2 & 1.90 & 49.50 & sand with gravel \\
\hline 10 & 51.0 & 4.0 & 333.2 & 1689.9 & 1.80 & 23.75 & clay \\
\hline 11 & 62.5 & 11.5 & 500.6 & 1808.8 & 1.95 & 49.17 & gravel \\
\hline 12 & $\infty$ & $\infty$ & 500.0 & 1808.8 & 2.00 & 46.00 & mudstone \\
\hline
\end{tabular}

We must, however, note that great care has to be taken when analyzing results of such a time-dependent analysis. When the waveform is simple, like a Ricker function, applying the window with smooth tapers at both ends in order to make the waveform causal has few effects on the timedependent analysis as shown in Figure 12. When the smoothing window of length $2.56 \mathrm{sec}$ enters into the $S$-wave portion, resonant frequencies start appearing (e.g., time window $2.4 \mathrm{sec}$ ); and, when the window encloses the main part of the signal, resonant frequencies become clearly visible (e.g., time window $3.0 \mathrm{sec})$. However, when the waveform becomes complex (for instance a summation of random Ricker functions or a natural wave), then time-dependent analysis is influenced by the smoothing window as shown in Figure 13. Both amplitude and resonant frequency location can be affected by the window shape. Moreover, the use of Tukey windows with ratios $1.0,0.5$, or 0.25 can give quite different results.

Figure 14 presents observed spectral ratios, showing a good agreement with theory for the transverse component.
We note that time windows for which resonant frequencies are visible in both transverse and radial components are rare. Hence, the transverse component has been chosen because it seems less influenced by soil heterogeneity, geometrical effects, and/or soil-structure interaction. Spectral ratio time windows shown in this figure have been chosen when the amplitude of the fundamental frequency was the largest; except for EQ03 (which shows a better overall agreement with theory for the shown time windows), for EQ04 time window 10.50-13.06 sec (which is used to show the quick change in the time of peak amplitudes), and for EQ17 (which shows a better overall agreement with theory for the shown time window). The following comments can be made on Figure 14.

- Generally speaking, 1D theory reproduces well the location of the observed fundamental frequency; however, fluctuations of the location are seen on observations.

- By comparing the location of the peak along the frequency axis (i.e., without comparing the amplitude of the peak) and despite small frequency shifts, EQ03 time window (a)

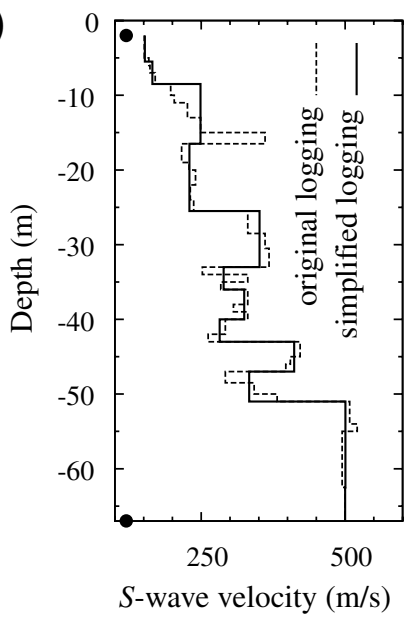

(b)

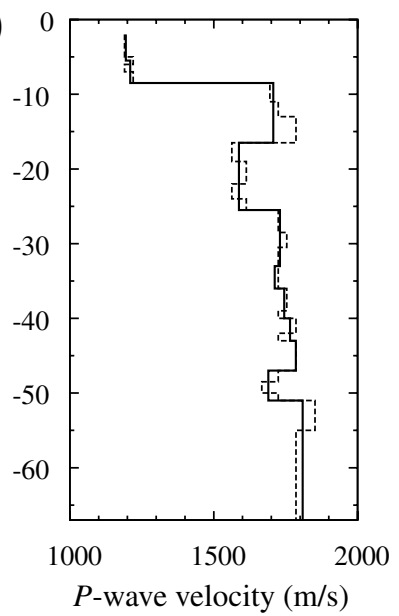

(c)

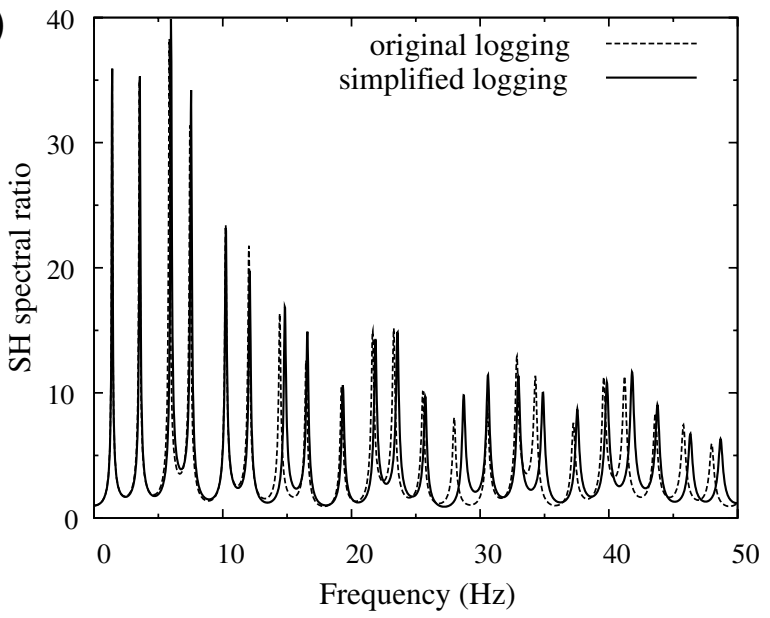

Figure 9. (a,b) Original and simplified PS logging. Upper and lower sensors (dots) are located at $2 \mathrm{~m}$ and $67 \mathrm{~m}$ below the free surface, respectively. (c) $\mathrm{SH}$ spectral ratio of original and simplified soil column. Low damping has been purposely used to better see the shift of resonant frequencies due to $S$-wave simplification. 
(a)

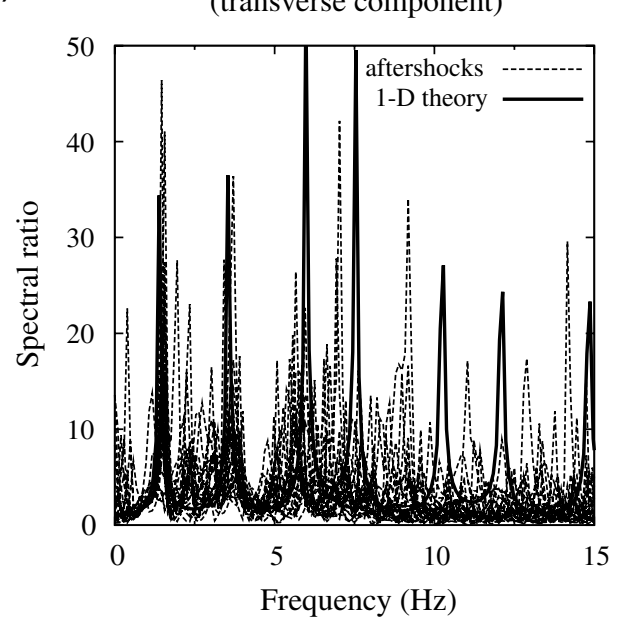

(b)

Fault parallel

(radial component)

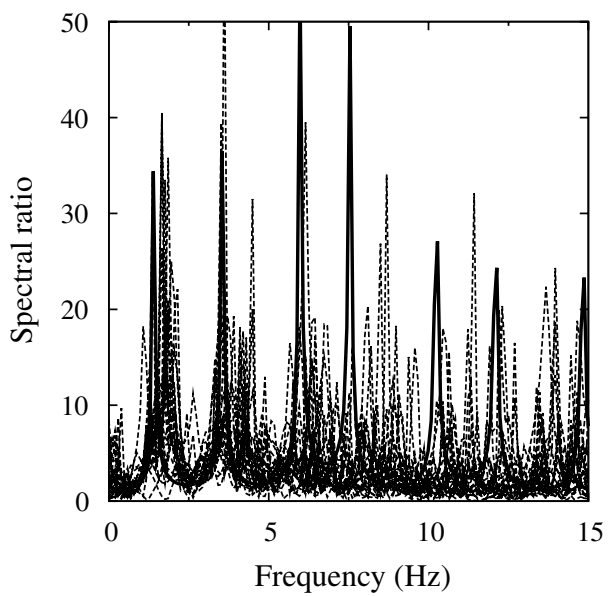

Figure 10. (a) Fault-normal spectral ratios. (b) Fault-parallel spectral ratios. Dashed line, spectral ratios performed on the $S$-wave portion of aftershocks chosen by sight; bold solid line, theoretical 1D spectral ratio for a vertically incident $S$ wave using the velocity logging. The frequency discretization of spectral ratios is $1 / 40.96 \mathrm{~Hz}$. A Parzen spectral window of bandwidth $0.1 \mathrm{~Hz}$ has been used to slightly smooth observed and theoretical ratios.

9.50-12.06 s shows a good agreement from the fundamental frequency (also called F1 hereafter, F2 being the second theoretical resonant frequency, F3 the third theoretical resonant frequency, and so on) to the seventh frequency. The two different time window for EQ03 and EQ4 exhibit the possible quick change in the time of peak amplitudes.

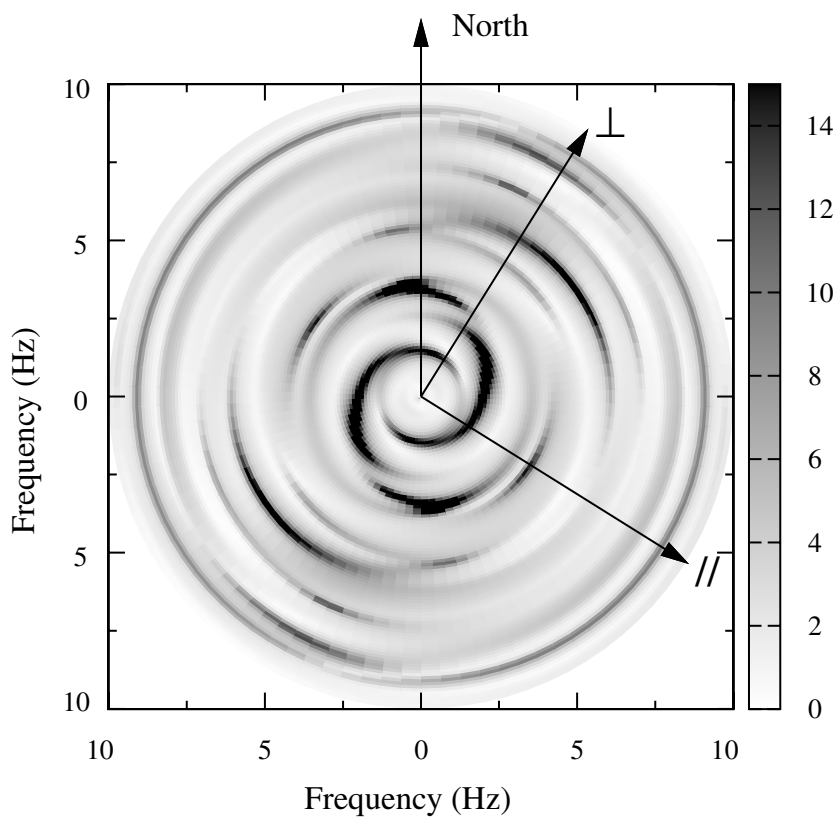

Figure 11. The $360^{\circ}$ spectral ratio of EQ06 in the frequency range 0 to $10 \mathrm{~Hz}$. Spectral ratios are computed by simultaneously rotating basement and downhole records from the north (represented by a vertical arrow). The coordinate $(0,0)$ is the frequency 0 , while the radius end represents the frequency $10 \mathrm{~Hz}$. Plots are symmetric with respect to the center $(0,0)$ due to the equality of Fourier spectra in two opposite directions. Axes denoted by $\perp$ and // indicate fault-normal direction (i.e., transverse component) and fault-parallel direction (i.e., radial component), respectively.
- No spectral ratio shows all the resonant frequencies for a unique time window. For instance, for EQ11, F1, F2, and F3 are visible, while F4 and F5 are not; however, F4 is visible on EQ10, while F2 and F3 are absent. This could mean that $1 \mathrm{D}$ wave propagation is not sufficient to thoroughly explain observations or that the smoothing window influences the shape of the ratios.

- For the aftershocks, inversion of damping factors in the frequency domain is not possible due to the previous comment.

- EQ09 and EQ20 clearly show a peak between F4 and F5, which would not be a shift of F5 because F5 can be seen on EQ21 or EQ23. Note that the amplitudes of input waves for these earthquakes are too low to assume soil nonlinearity.

- Except for the resonant frequency F5 of EQ09 and EQ20, the locations of the resonant frequencies are well reproduced up to $12 \mathrm{~Hz}$ by the $1 \mathrm{D}$ theory.

By considering all the spectral ratios of Figure 14 and the possible influence on peak location of soil heterogeneity, geometrical effects, soil-structure interaction, incidence angle of the incoming wave, and/or smoothing window effects, we conclude that the $S$-wave velocity logging is accurate in the linear domain for the transverse direction and does not need to be inverted. The explanation of the shift of the fundamental frequency in the radial direction would need further research; consequently, the following is based on the conclusions drawn up for the transverse direction.

As for the damping factors of each layer used to take into account intrinsic absorption by anelasticity and scattering by heterogeneity, we assume it to be of the form $h=$ $h_{0} f^{-\alpha}$ (e.g., Satoh et al., 2001) and constant along the soil column. Because, for this study, inversion of damping factors in the frequency domain could be influenced by other phenomenon, we adjust it manually by comparing simulations 

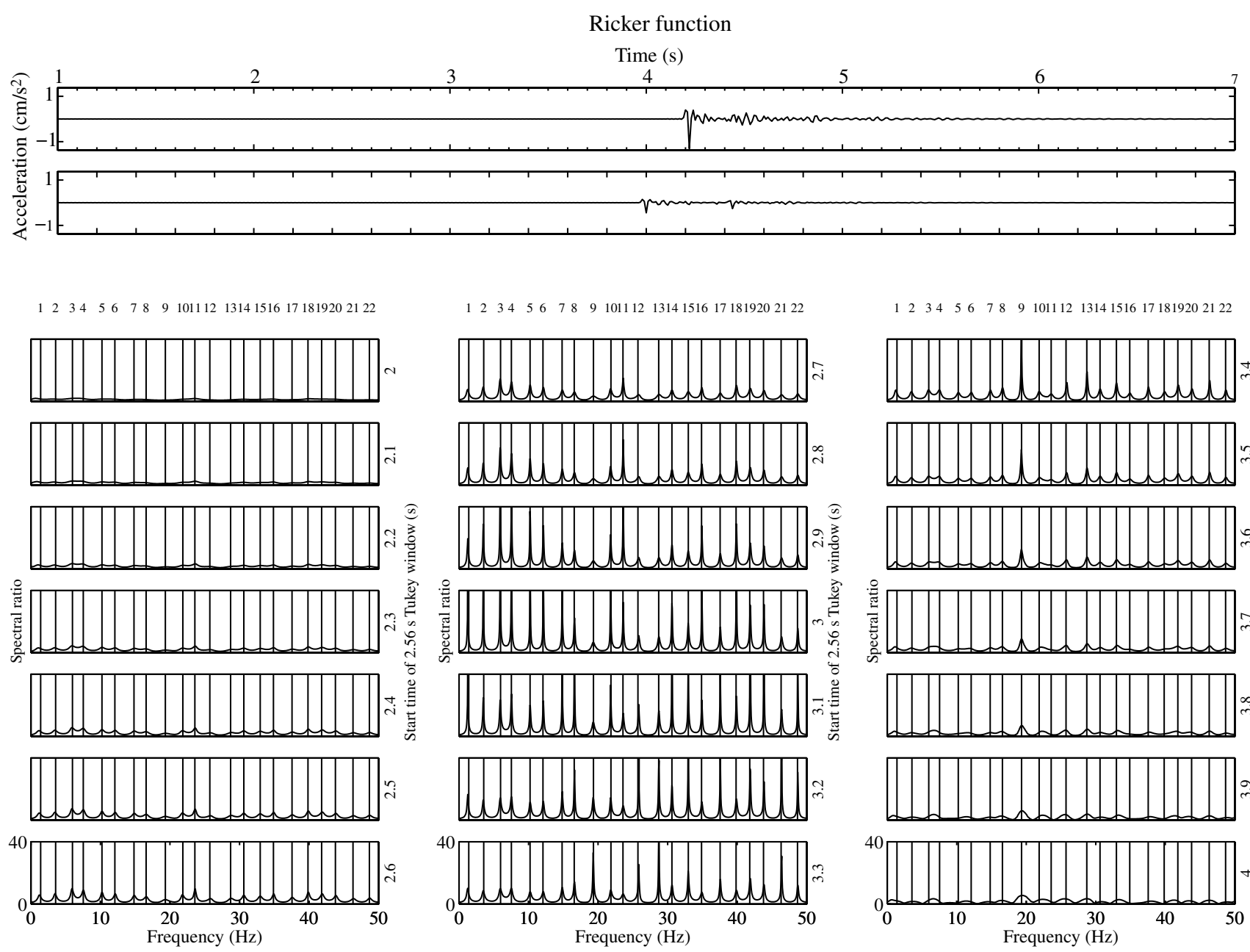

$\begin{array}{lllllll}12 & 34 & 56 & 78 & 9 & 101112 & 13141516171819202122\end{array}$
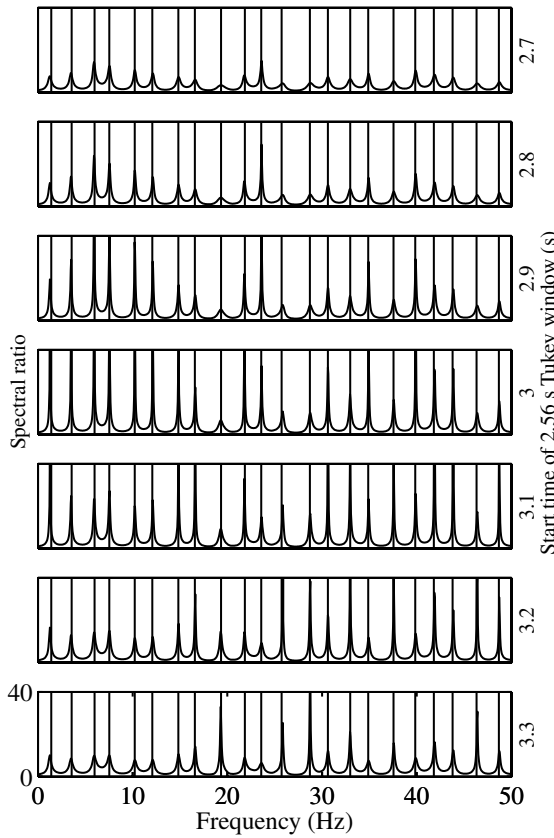

$1223456 \quad 78 \quad 910111213141516171819202122$
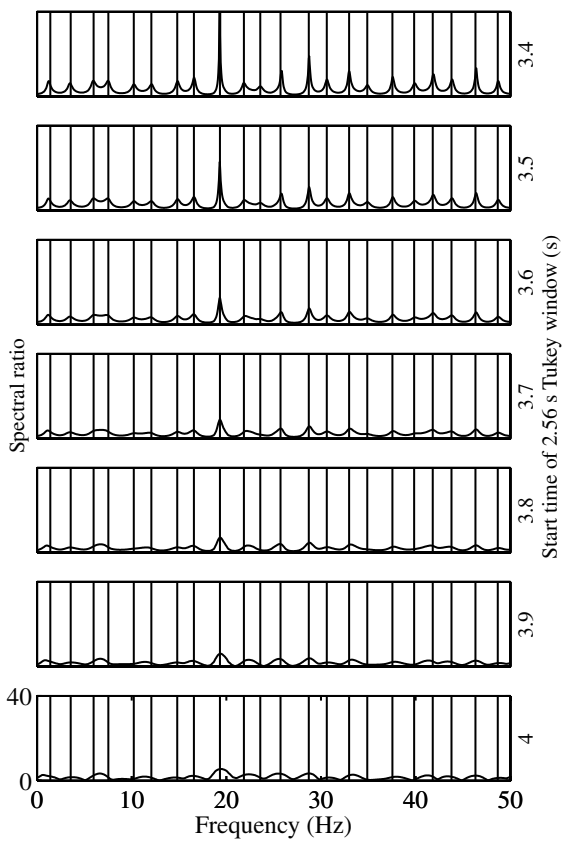

Figure 12. Time-dependent spectral ratios analysis performed between downhole and basement waveform when the input wave is a Ricker function of pseudofrequency $25 \mathrm{~Hz}$. Top: basement and downhole waveforms. Ratios are computed using 2.56 sec Tukey windows with ratio 1 and translated by $0.1 \mathrm{sec}$ (i.e., $96 \%$ of overlapping). Numbers on the right side of each panel indicate start time of Tukey windows. $X$ and $Y$-axes boundaries of spectral ratios are indicated on bottom-most panels. No smoothing window are applied. Vertical lines on spectral ratios panels indicate theoretical resonant frequencies of the velocity logging, and theoretical resonant frequencies are numbered by integers above the top-most panels of spectral ratios.

and observations in the time domain and find that $h_{0}=0.13$ and $\alpha=0.6$ fit the data well. Figure 15 shows simulations of basement and downhole acceleration, as well as deconvolution from basement and downhole waveforms. Reproduction of waveforms in transverse and radial directions is acceptable during the $S$-wave portion for a 1D model. Phase shift for the radial component is consistent with the fact that $S$-wave logging underestimates the observed fundamental frequency, which is shifted to high frequencies (as seen in Fig. 11). We note that other simulations of aftershocks show a good agreement as well when using the same damping factors. This good agreement justifies one more time that the $S$-wave velocity logging is accurate in the linear domain.

In the following section, we will compute spectral ratios on the mainshock records and describe the inversion by a genetic algorithm of the $S$-wave velocity structure and damping factors.

\section{Inversion of the Soil Structure during the Mainshock}

In order to detect possible nonlinear behavior of the CTI borehole soil column during the 2005 Fukuoka Prefecture Western Offshore earthquake, we perform a time-dependent spectral ratios analysis in the major and minor axes. For this time-dependent analysis, the beginning of the window is fixed to $3 \mathrm{sec}$ (i.e., before the onset of the $S$-wave portion), and the end of the window is extended incrementally. Spectral ratios in the transverse and radial directions are shown in Figure 16 (two top panels) when the amplitude of the fundamental mode is the highest in the transverse direction. At that time, the length of the smoothing window is $5.9 \mathrm{sec}$ (i.e., it mainly covers the $S$-wave portion of the signal). The fundamental frequency originally at $1.41 \mathrm{~Hz}$ is shifted to $1.15 \mathrm{~Hz}$ in the transverse direction and to $1.32 \mathrm{~Hz}$ 

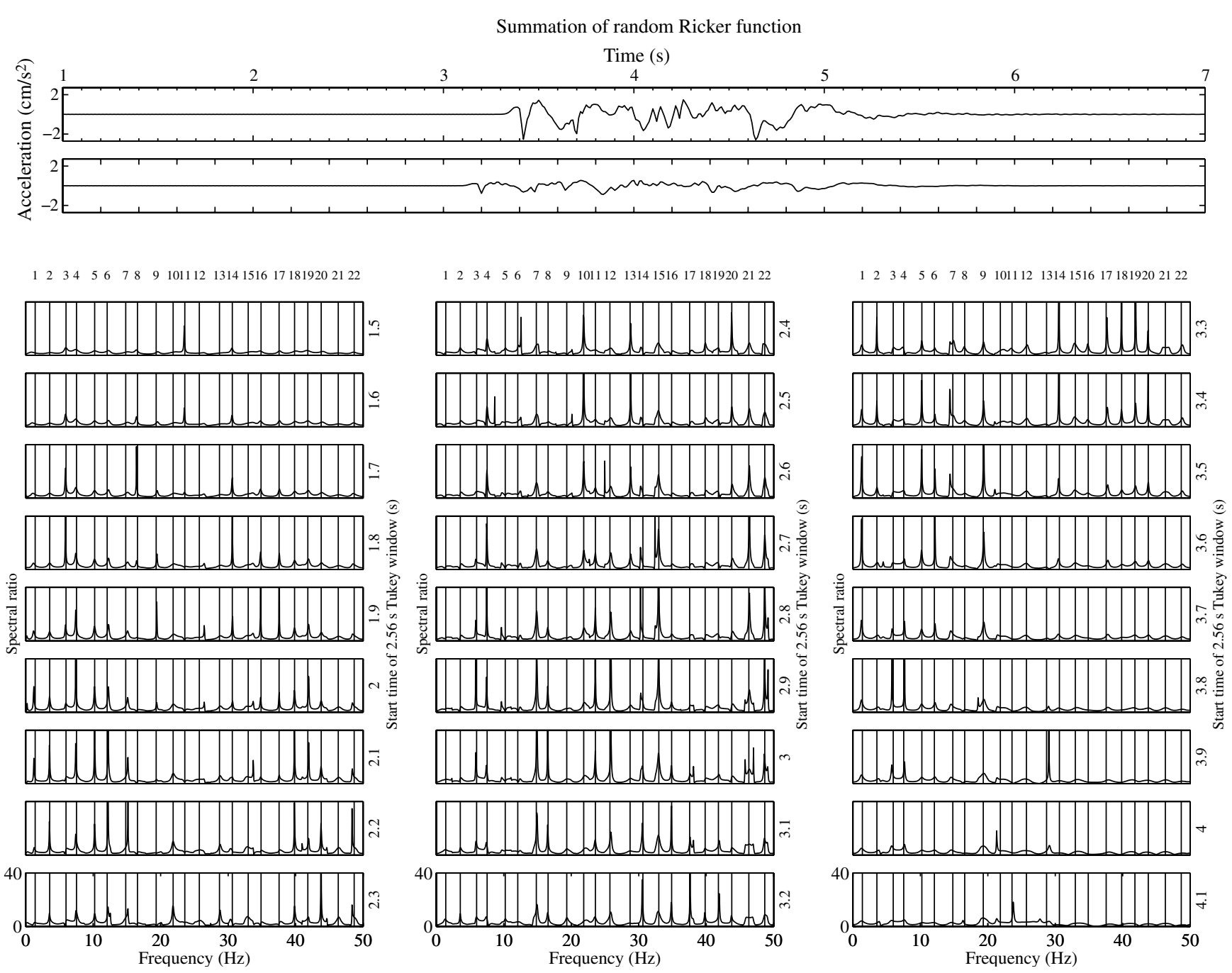

Figure 13. Time-dependent spectral ratios analysis performed between downhole and basement waveforms when the input wave is a summation of ten Ricker functions for which pseudofrequency is randomly chosen within the interval $0.5-25 \mathrm{~Hz}$.

in the radial direction. (The fact that the radial mode has a higher frequency than the transverse one is consistent with observations made on aftershocks.) In both directions, the shift toward low frequencies of observed peaks F1, F3, F5, and F6 is typical of nonlinear behavior of soft sediments (i.e., decrease of the shear modulus). However, an inconsistency remains for F4. It is shifted toward low frequencies in the radial direction, while it is shifted toward high frequencies in the transverse direction. According to 1D theory, the decrease of $S$-wave velocity of some layers can shift certain resonant frequencies toward low frequencies and leave others unchanged; however, it is impossible that this decrease shifts resonant frequencies toward high frequencies as seen for $\mathrm{F} 4$ in the transverse direction. A $360^{\circ}$ spectral ratio, shown in Figure 17, reveals that F4 is present for almost all azimuths but disappears in the vicinity of the fault-normal direction (i.e., transverse component) and appears to be shifted to higher frequencies. This shift could, therefore, be due to geometrical effects and/or soil-structure interaction. We note that this peak appears approximately at the location of the additional peak seen for EQ09, EQ12, and EQ20 of Figure 14. We also note that $\mathrm{F} 2$ and $\mathrm{F} 3$ form a clear circle in accordance with 1D theory, while F1 exhibits the same spiral pattern as observed on some aftershocks (e.g., Fig. 11). As a result, F4 in the transverse direction will be ignored in the 1D inversion.

In order to quantify $S$-wave velocity reduction that causes shift of resonant modes toward low frequencies, we use a genetic algorithm to invert observed the spectral ratios presented in Figure 16 using the Thomson-Haskell propagator matrix method. Because the $S$-wave logging transfer function is accurate for simulations of aftershocks, the search space of $S$-wave velocity is limited to values smaller than or equal to the $S$-wave logging velocity. However, because of the shift toward high frequencies of F4 in the transverse direction (which is inconsistent with the 1D assumption), the common objective function, which tends to minimize the integrated residuals between observed and theoretical 

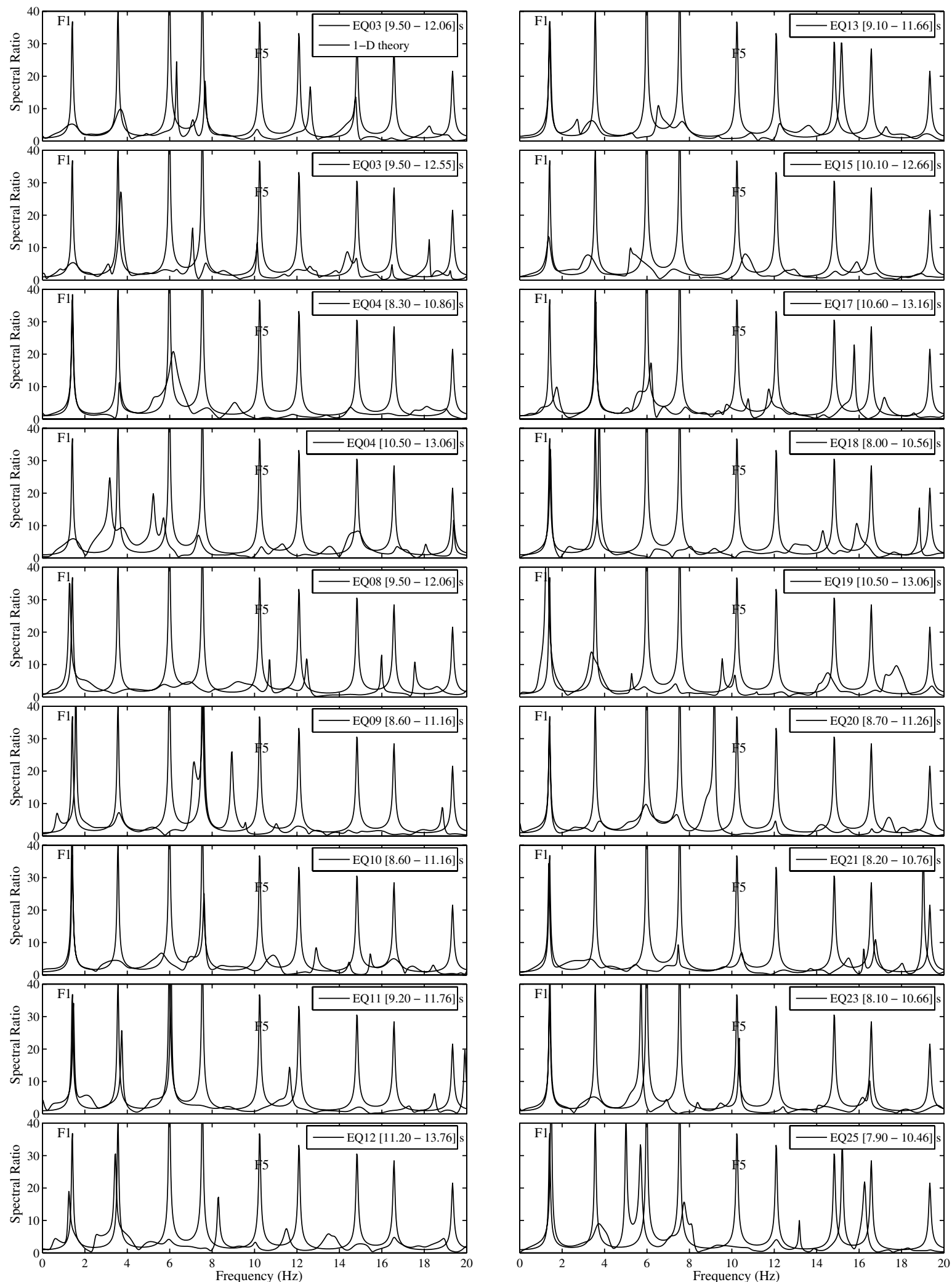

Figure 14. Observed spectral ratios computed within the $S$-wave portion of small aftershocks using time-dependent analyses (bold lines) plotted together with 1D theory (thin lines) in the transverse direction. Theoretical spectral ratios are plotted using a constant damping of the form $h=h_{0} f^{-\alpha}$ with $h_{0}=0.01$ and $\alpha=0.6$. Both observed and theoretical ratios are smoothed using a Parzen window of bandwidth $0.1 \mathrm{~Hz}$. EQ03 and EQ04 are plotted two times with different time windows to emphasis the rapid variation in time of the shape of the ratio (especially the amplitude of the peak). Theoretical resonant frequencies F1 and F5 are annotated to facilitate the reading of the figure. 

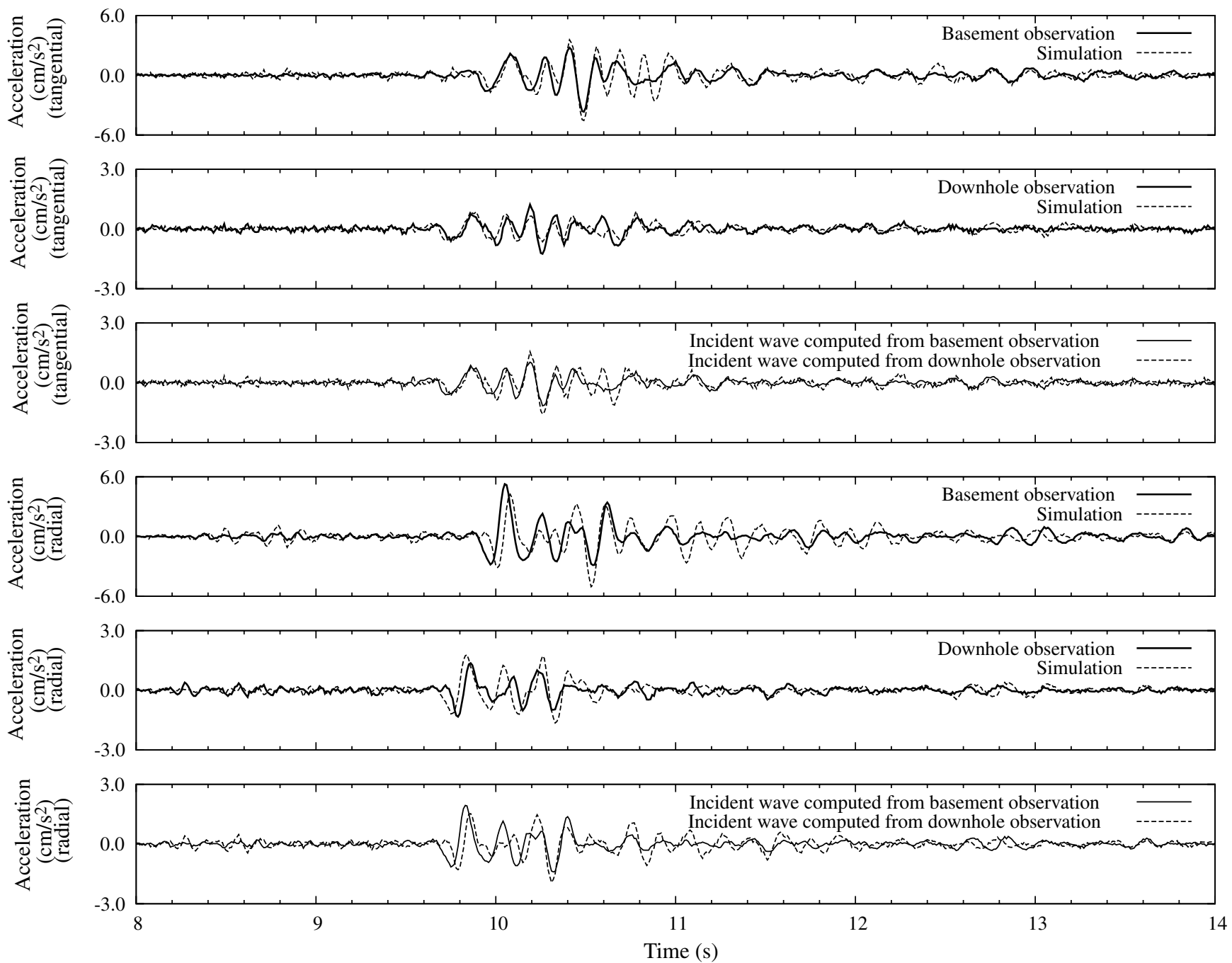

Figure 15. Simulations and deconvolutions of EQ11 in transverse and radial directions using $S$-wave velocity logging and constant damping factor along the soil column of the form $h=h_{0} f^{-\alpha}$ with $f$ as the frequency, $h_{0}=0.13$ and $\alpha=0.6$.

spectral ratios (e.g., Satoh et al., 1995) cannot be used for this study. Therefore, we introduce a simple objective function that is independent of the global shape of spectral ratios and is of the form

$$
E(\mathbf{x})=\frac{\sum_{i=1}^{n_{P F}} \frac{\left|P F_{i}^{o b s}-P F_{i}^{\text {the }}(\mathbf{x})\right|}{P F_{i}^{o b s}}}{\sum_{j=1}^{n_{P F}} P F_{j}^{o b s}}+\frac{\sum_{i=1}^{n_{P A}} \frac{\left|P A_{i}^{o b s}-P A_{i}^{\text {the }}(\mathbf{x})\right|}{P F_{i}^{o b s}}}{\sum_{j=1}^{n_{P A}} P A_{j}^{o b s}},
$$

with $\mathbf{x}$ as the vector containing parameters to invert, $P F_{i}^{o b s}$ the $i$-th observed peak frequency, $P F_{i}^{\text {the }}$ the $i$-th theoretical peak frequency, $P A_{i}^{o b s}$ the $i$-th observed peak amplitude, $P A_{i}^{\text {the }}$ the $i$-th theoretical peak amplitude, $n_{P F}$ the number of peak frequency to use, and $n_{P A}$ the number of peak amplitude to use. In order to give more weight to low-frequency peaks, each member is divided by $P F_{i}^{o b s}$. Normalization by $\sum_{j=1}^{n_{P F}} P F_{j}^{o b s}$ and $\sum_{j=1}^{n_{P A}} P A_{i}^{o b s}$ is done to avoid overweighting the frequency or amplitude portions.

This objective function focuses on the location of peaks along the frequency axis and on the amplitude of peaks.
Peaks used in an inversion can be chosen at will to calculate the objective function. We note that this objective function has the virtue of being the summation of linear functions of the form $\left|X_{i}^{o b s}-X_{i}^{\text {the }}(\mathbf{x})\right|$, which makes its shape simple for inversion techniques in an $n$-dimensional space. Its disadvantage resides in the fact that one has to know a priori which peaks have to be inverted.

Neglecting the fact that large damping factors can increase $S$-wave velocities due to their contribution in the complex shear modulus (i.e., $G^{*}=G(1+2 i h)$, with $G$ the shear modulus and $h$ the damping value), we perform two independent inversions by first inverting $S$-wave velocities to shift theoretical peaks to low frequencies, and then damping factors to adjust peak amplitudes (i.e., first and second member of residual $E(\mathbf{x})$ are used independently, and normalization by $\sum_{j=1}^{n_{P F}} P F_{j}^{o b s}$ and $\sum_{j=1}^{n_{P A}} P A_{j}^{o b s}$ is omitted). Because the transverse and radial observed resonant frequencies are close and considering the fact that fluctuations of peak location is possible due to phenomena other than the 1D assumption, we 

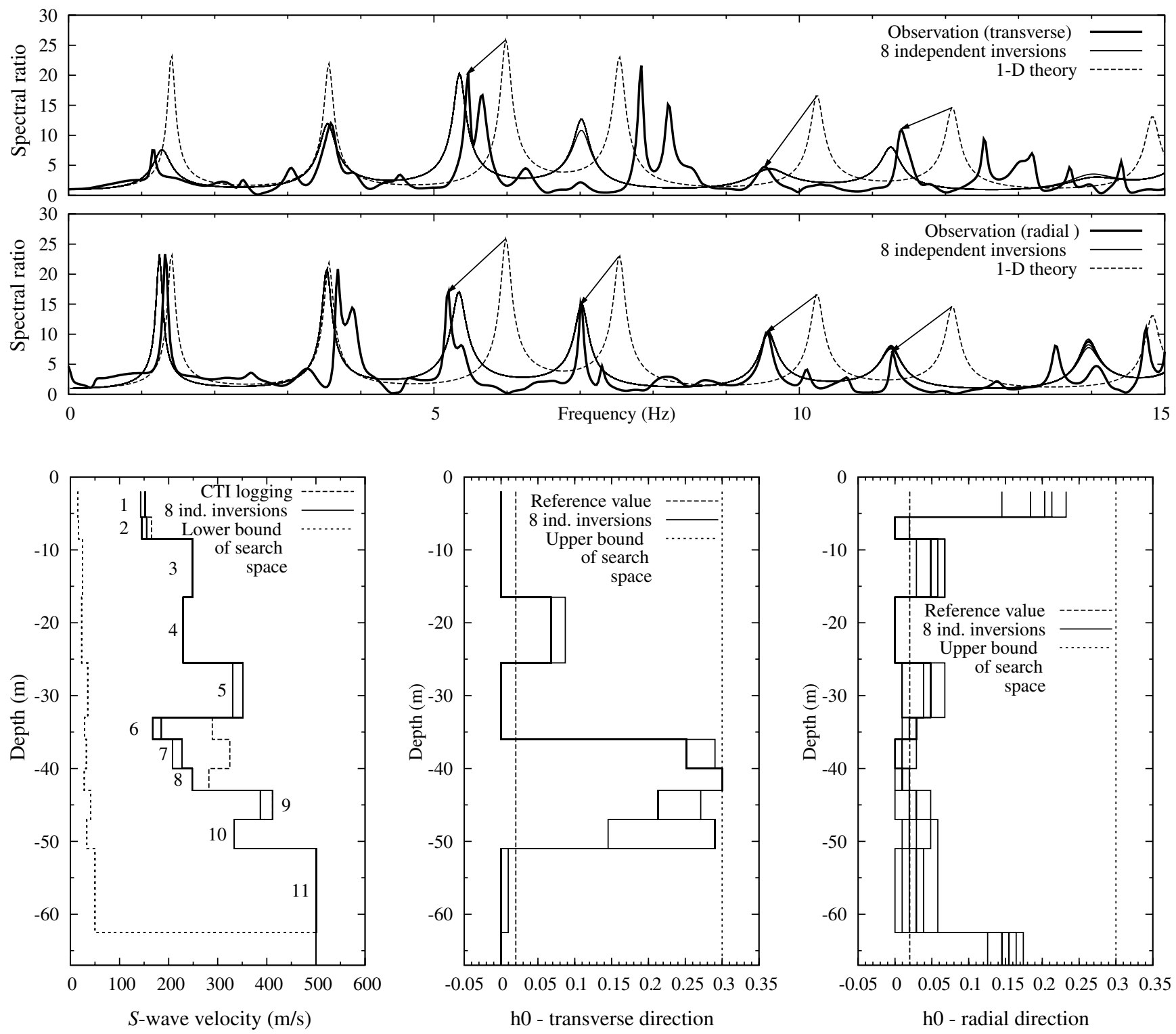

Figure 16. First two top panels: spectral ratios observed in transverse and radial direction (bold solid line) plotted together with $S$-wave logging transfer function (dashed-line) and inverted spectral ratios (thin solid lines) from 8 independent (ind.) inversions. Logging transfer function has been computed using a constant damping of the form $h=h_{0} f^{-\alpha}$ with $h_{0}=0.02$ and $\alpha=0.6$. Bottom left panel: eight inverted $S$-wave velocity structures (thin solid lines) plotted with logging structure (dashed line). A dashed line represents the lower bound of the search space, the upper bound being the logging's structure. Numbers indicate layers of Table 3. Bottom middle and right panels: eight inverted damping factors in transverse and radial directions (thin solid lines). The reference value (bold solid line) is the one used to computed theoretical ratios of the top panels. A dashed line represents the upper bound of the inversion.

use the mean of observed resonant frequencies between transverse and radial components for $P F_{i}^{o b s}$ except for F4, for which the value of the radial component has been chosen. For peak amplitude, we perform independent inversions for transverse and radial components due to the strong discrepancy of amplitudes in the fundamental mode. Table 4 summarizes frequencies and amplitudes of peaks targeted for the inversion.

The flowchart of the inversion is presented in Figure 18. Prior to the genetic algorithm optimization, a Monte Carlo search is performed on five populations of size 2048 binary individuals in order to explore the search space. Each individual represents the $S$-wave velocity of 11 layers ( $S$-wave velocity of the bedrock has not been inverted because it is assumed to be linear elastic). The minimum bound for the $S$-wave velocity of each layer is fixed to 0.1 times the $S$-wave velocity of the logging. The maximum bound is the $S$-wave velocity from the logging itself because it has been corroborated using small aftershocks. A total of 4 bytes per layer has been used so that the interval [0.1-1.0] is divided into 16 values (called inversion factors hereafter). The total number of possible solutions is therefore $2^{4 \times 11}=1.759 \times 10^{13}$. 


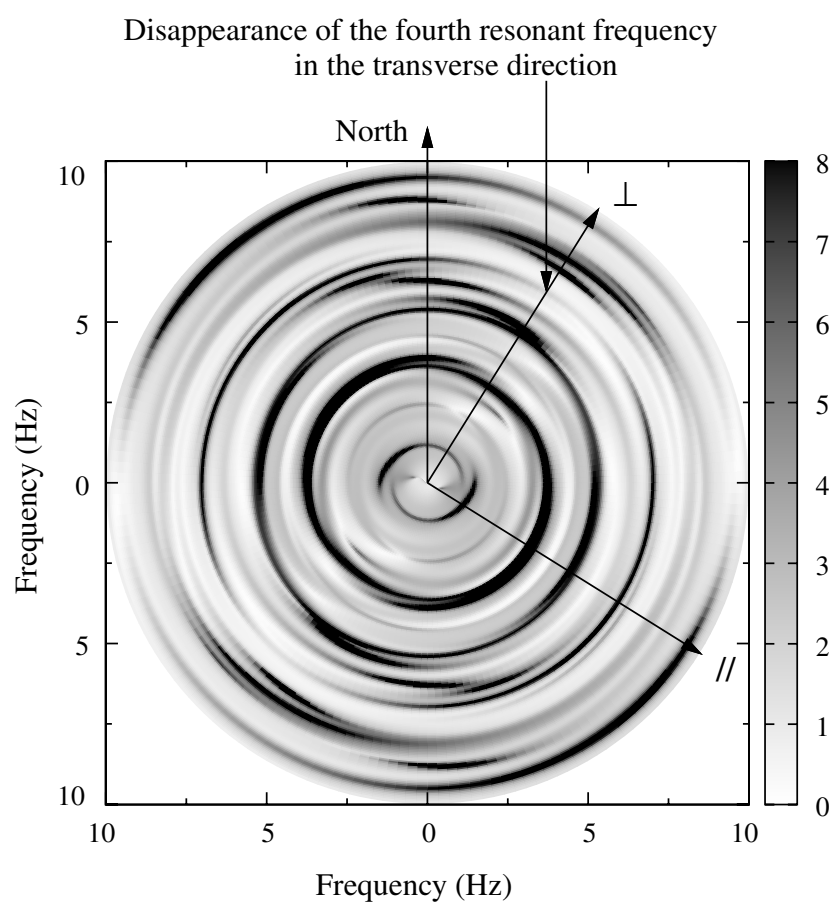

Figure 17. The $360^{\circ}$ spectral ratio computed during EQ01. Axes denoted by $\perp$ and // indicate the fault-normal direction (i.e., transverse component) and the fault-parallel direction (i.e., radial component), respectively.

Coefficient $h_{0}$ of the damping factors are inverted for each soil layer and the bedrock within the interval $[0.0-0.3]$ is discretized into 32 inversion factors (i.e., 5 bytes per layer). The total number of possible solutions is $2^{5 \times 12}=1.153 \times 10^{18}$. The exponent $\alpha$ of the damping factors are not inverted, and they are fixed to 0.6 .

Individual transfer functions are computed using the Thomson-Haskell propagator matrix method and are smoothed with the same Parzen window bandwidth used to smooth observed ratios (i.e., $0.1 \mathrm{~Hz}$ ). Their objective function is evaluated by $E(\mathbf{x})$. Once the Monte Carlo search is terminated, the best 1024 individuals found are used to generate the initial genetic algorithm population of 1024 individuals. If the termination criterion is not reached (i.e., a small residual or a large number of population), a selection by tournament is performed with a pool of 10 individuals in order to generate the reproduction population of size 1024 . Elitism is activated so that if the best 10 individuals are not present in the reproduction population, they are automatically added. The new population is generated with a crossover probability of $85 \%$ and a mutation probability of $0.1 \%$. If crossover does not occur, random individuals are generated in the new population to maintain the genetic diversity.

In order to avoid convergence to local minima, the summation of the distance between inversion factors of individuals (i.e., $N(N+1) / 2$ additions with $N$ as the number of individuals in a population) is monitored; and, if this summation drops below a threshold, then a new population is

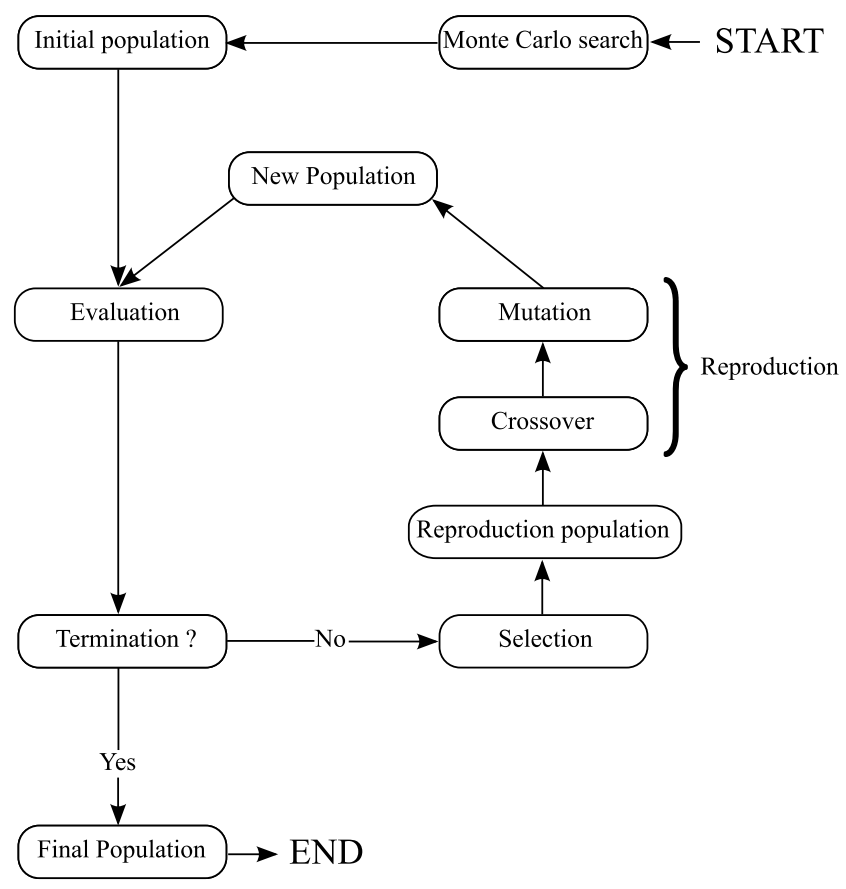

Figure 18. Flowchart of genetic algorithm inversion preceded by a Monte Carlo search.

generated at random. An example for an inversion of the evolution of the global minimum residual, the minimum residual of new populations, and the summation of distance between individuals is shown in Figure 19. From population number 20 , the global minimum does not evolve anymore, and the summation of distances between individuals starts decreasing rapidly around population 30 . This means that a possible local minimum has been found and that populations start stagnating (i.e., all individuals in a population become identical, and offsprings are identical to their parents). In order to avoid such a possible local minimum, a random population is generated when the summation of distance between individuals goes below a threshold fixed to 100 in terms of summation of inversion factors. This has almost the effect of starting the inversion from a totally new population; however, the best individuals found so far are still injected inside the reproduction population and can either be improved or participate to build new best individuals in another region of the search space. As a result, better individuals are found around population number 50 and 180 as shown in Figure 19.

In order to guarantee the robustness of the solution, eight independent inversions are made to invert either $S$-wave velocity in the first step or damping factors in the second step. Evolution of the global minimum residual for eight independent inversions of $S$-wave velocity is shown in Figure 20. The first five populations correspond to a Monte Carlo search, then the genetic algorithm optimization is activated, and a fast convergence is visible. After 200 populations, even if a unique minimum is not found, the three distinct minima 


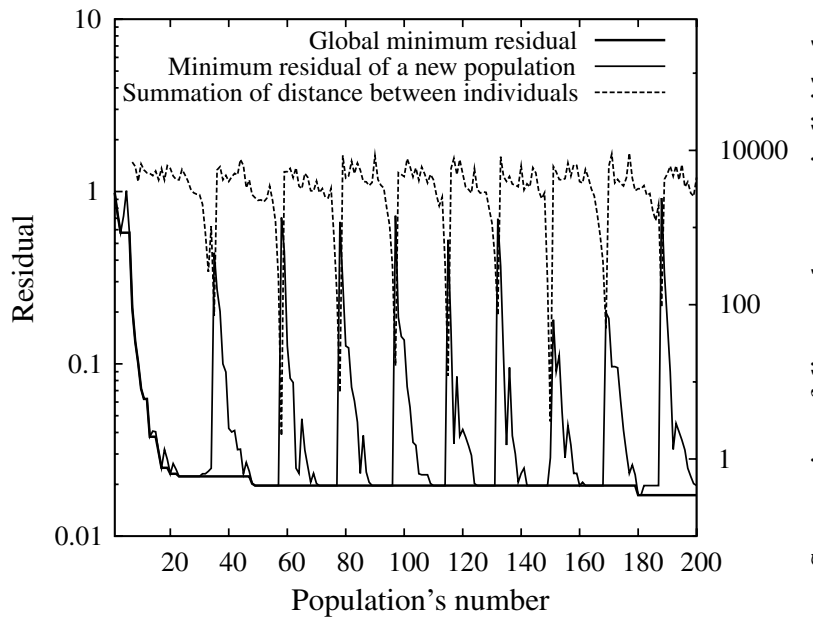

Figure 19. Example for an inversion of the evolution of the global minimum residual (bold line), the minimum residual of a new population (thin line), and the summation of distance between individuals (dashed line).

lead to close velocity profiles shown on the bottom left panel of Figure 16; hence, this guarantees the robustness of the solution. Inverted damping factors are shown in the bottom middle and right panels of Figure 16. Even if several minima are found (especially in the radial direction), they are close to each other, which guarantees the quality of the convergence. Corresponding spectral ratios are shown in the first two top panels of Figure 16; for some modes, we note that small shifts between inverted resonant frequencies and observed ones are due to the fact that the mean of resonant frequencies between transverse and radial component has been inverted. Accuracy of the inversion is shown in Table 4, which compares targeted and inverted peak frequency and amplitude. We also note that, by inverting only F1, F2, F3, F5, and F6 in the transverse direction, a similar velocity profile is found and F4 goes naturally to $7.0 \mathrm{~Hz}$, thereby confirming that the shift toward high frequency of F4 is not consistent with a 1D assumption.

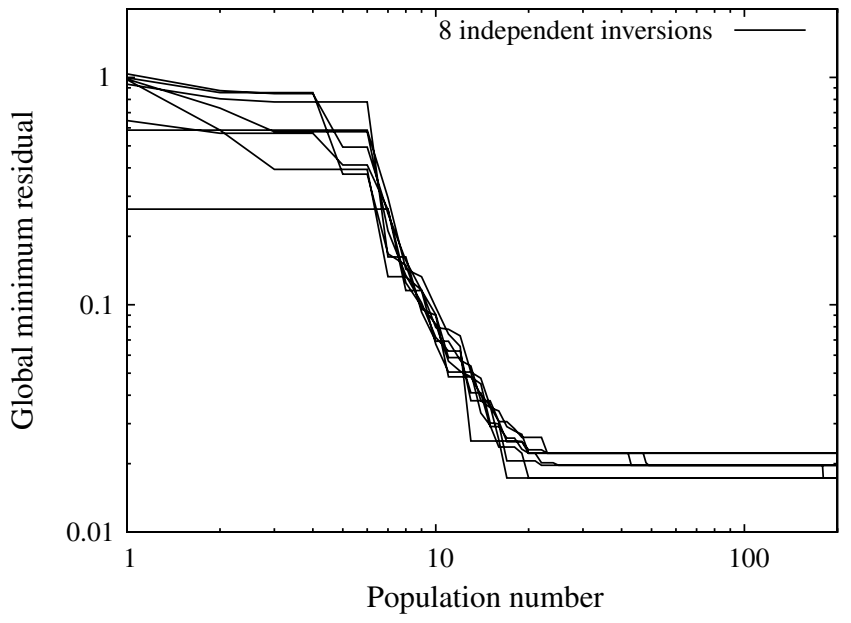

Figure 20. Evolution of global minimum residual $E(\mathbf{x})$ of eight independent inversions with respect to population number.
Moreover, in order to reinforce the inversion obtained by using the objective function $E(\mathbf{x})$ presented previously, we perform a separate inversion in the transverse direction by using the traditional objective function, which tends to minimize the integrated residuals between observed and theoretical spectral ratios (e.g., Satoh et al., 1995). Parameters of the search space and the discretization are identical, but $S$-wave velocity and damping factors are inverted at the same time. To avoid the directional effect on $\mathrm{F} 4$ as shown previously, the integration is performed from 0.1 to $7.0 \mathrm{~Hz}$ and from 9.0 to $12 \mathrm{~Hz}$. Results are shown in Figure 21. The localization of the significant decrease of the $S$-wave velocity is consistent with the previous results; the nonlinear behavior is found to appear in layers 6-9. As for the damping, the order of magnitude is globally the same along the soil column, but discrepancies are found for layers 1 and 5 . We note that an inversion performed by integrating the residual from 0.1 to $12 \mathrm{~Hz}$ includes the directional effect and leads to different results.

Spectral ratios used for the inversion being taken over the entire $S$-wave portion, the inverted profile can be used to perform time history simulations of this $S$-wave portion. Acceleration simulations of the basement are shown in Figure 22. The agreement with observations is acceptable in both directions. Nevertheless, observed radial accelerations are often underestimated by the simulation, denoting an overestimation of inverted damping factors in this direction. This can be due to the fact that spectral ratios in both transverse and radial directions have been selected when the amplitude of the spectral ratio in the transverse direction was the highest, whereas the amplitude of the spectral ratio in the radial direction was not at its highest point.

With regard to the localization of nonlinearity with depth, the reduction of the $S$-wave velocity around $35 \mathrm{~m}$ depth is consistent with the variation of peak frequency of the soil column presented in Figure 23. The fact that the observed second resonant frequency did not shift under loading, as seen in Figure 16, means that significant nonlinear behavior could take place only within layers 6 and 7, which have no influence on the second mode. We also note that, in the transverse direction, the increase of damping factors is not always consistent with the decrease of $S$-wave velocity. The ratio of the length of the decrease of $S$-wave velocity to the length of the increase of damping is approximately $93 \%$. This can be due to the fact that the inverse solution is not the best one or that other phenomena that influence the shape of the ratio, such as soil-structure interaction or geometrical effects, are included in the inversion. This discrepancy is even more obvious in the radial direction. This suggests that, for this site, independent inversions should be carried out in the transverse and radial directions.

We also note that damping factors adjusted during the aftershocks seem too high compared to those inverted during the mainshock. This can be due to the fact that the damping found for aftershocks is an equivalent damping manually adjusted in the time domain (because the amplitude of the 
Table 4

Frequencies and Amplitudes of Peaks Targeted for the Inversion*

\begin{tabular}{|c|c|c|c|c|c|c|c|c|c|}
\hline \multirow[b]{3}{*}{ Frequency } & & & & \multicolumn{6}{|c|}{ Peak Amplitude } \\
\hline & \multicolumn{3}{|c|}{ Peak Frequency } & \multicolumn{3}{|c|}{ Transverse } & \multicolumn{3}{|c|}{ Radial } \\
\hline & B & $\mathrm{T}$ & I & B & $\mathrm{T}$ & I & B & $\mathrm{T}$ & I \\
\hline $\mathrm{F} 1$ & 1.41 & 1.24 & 1.24 & 25.32 & 7.58 & 7.58 & 25.32 & 23.30 & 23.28 \\
\hline $\mathrm{F} 2$ & 3.56 & 3.56 & 3.54 & 28.27 & 11.97 & 11.92 & 28.27 & 20.82 & 20.71 \\
\hline F3 & 5.86 & 5.34 & 5.35 & 32.57 & 20.32 & 20.30 & 32.57 & 17.04 & 16.97 \\
\hline $\mathrm{F} 4$ & 7.74 & 7.00 & 6.98 & 25.05 & - & 10.81 & 25.05 & 15.00 & 14.97 \\
\hline F5 & 10.22 & 9.56 & 9.59 & 19.93 & 4.73 & 4.51 & 19.93 & 10.31 & 10.25 \\
\hline F6 & 12.08 & 11.33 & 11.32 & 17.55 & 10.86 & 8.09 & 17.55 & 7.13 & 7.69 \\
\hline
\end{tabular}

*Peak frequency and amplitude before inversion (B) (i.e., using $S$-wave logging), targeted for the inversion (T) (i.e., selected from observed ones), and inverted (I). Inverted values of peak frequency correspond to results of $S$-wave inversions.

resonant peaks in the frequency domain were not constant); consequently, this equivalent damping is mainly controlled by scattering around the fundamental frequency and is not comparable with damping factors inverted in the frequency domain for the mainshock. Besides, as noted by Satoh et al. (2001), the reason why the strain dependence of damping factors is not as significant as that of shear modulus ratios may be because scattering attenuation is dominant in the low-strain range.

Shear modulus ratios versus shear strain is compared in Figure 24 with laboratory test results from Seed and Idriss (1970b) for sand and gravel and from Vucetic and Dobry (1991) for clay (due to the fact that peak amplitude is more sensible than peak frequency to use when doing spectral ratios; only shear modulus reduction is compared with standardized curves). Shear strain levels of layers are calculated using the $S$-wave velocity logging and a constant damping along the soil column adjusted to $5 \%$ to best reproduce the basement and downhole acceleration time histories. For sand and gravel layers, it is clear that results of the inversion are situated above standardized curves. This result can be explained by the following facts:

- For layers below $40 \mathrm{~m}$ depth, the effective vertical stress (overburden pressure) is larger than the one used to draw the upper bound of the standardized curves; and, because the higher the effective vertical stress the lower the shear modulus reduction with respect with shear strain, shear modulus ratios for layers 9 or 11 are consistent with standardized curves (because the shear modulus reductions are located above the standardized curves).

- For layers between the free surface and $40 \mathrm{~m}$ depth, strain levels calculated by using the $S$-wave velocity logging and a constant damping of 5\% might be higher than in reality due to the dissipation of energy that took place in layers 6, 7, and 8 ; consequently, shear moduli found by inversion are consistent with the shift of resonant modes, but shear strain levels might be overestimated by the 1D linear assumption.

For clay, standardized curves show a clear dependence of shear modulus ratios with respect to plasticity index, especially for large shear strain levels. Because the plasticity indexes for the soil column of this study are unknown, an accurate comparison is not possible.

\section{Conclusion}

In order to detect nonlinear behavior of soft soil during the 2005 Fukuoka Prefecture Western Offshore earthquake, we have first corroborated the $S$-wave velocity logging in the linear elastic domain by using time-dependent spectral ratios analyses. Despite a good agreement between observation and theory in the transverse direction for several resonant modes, the observed fundamental mode in the radial direction exhibits a higher resonant frequency. We found by using $360^{\circ}$ spectral ratios that a clear drift of the fundamental mode was visible in the radial direction due to either soil heterogeneity, geometrical effects, and/or soil-structure interaction. Moreover, because of a large inhomogeneity of peak amplitudes amongst aftershocks, frequency-dependent damping factors have been adjusted in the time domain.

Then, to show qualitative evidence of nonlinearity during the mainshock, we have performed a time-dependent spectral ratios analysis, which showed that several resonant modes were shifted toward low frequencies, thus pointing out shear moduli reduction for high shear strain levels.

Finally, in order to evaluate the degree of nonlinearity, we have used a genetic algorithm to invert the equivalent linear $S$-wave velocity and damping factors on the $S$-wave portion via the Thomson-Haskell propagator matrix method. Because of effects inconsistent with the 1D assumption in the transverse direction, common objective functions that minimize integrated residuals between observed and theoretical spectral ratios could not be used. We have, therefore, introduced an objective function depending only on peak frequency and peak amplitude in order to choose which modes to invert. We note that in cases where soil heterogeneity, geometrical effects, and/or soil-structure interaction affect the 1D assumption, transverse and radial direction could be inverted separately. The robustness of the inversion on $S$-wave velocity was shown by performing eight independent inversions that lead to minima associated with close velocity 

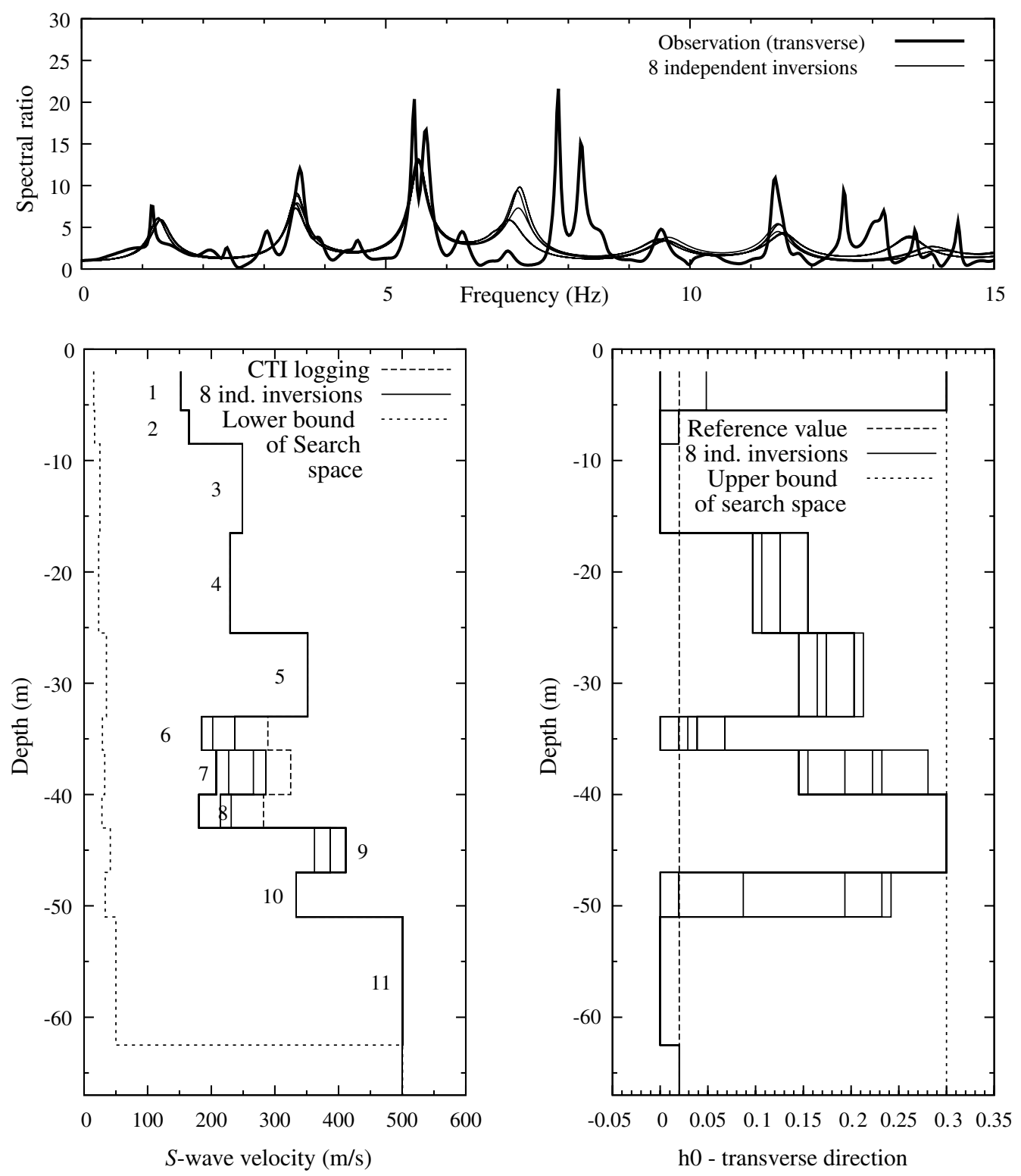

Figure 21. Results of eight independent inversions obtained by using the conventional objective function (e.g., Satoh et al., 1995). Top panel: spectral ratios observed in transverse direction (bold solid line) plotted together with inverted spectral ratios (thin solid lines) from eight independent inversions. Bottom left panel: eight inverted $S$-wave velocity structures (thin solid lines) plotted with logging structure (dashed line). Bottom right panel: eight inverted damping factors in transverse direction (thin solid lines).

profile; thus guaranteeing a convergence toward a probable global minimum.

\section{Data and Resources}

The borehole station used in this study is the CTI Engineering Co., Ltd., borehole station (http://www.ctie.co.jp/ earthquake/eq_20050320.html). Seismograms used in this study were provided by K-NET, KiK-net, Fukuoka Prefecture seismic intensity meter network, and CTI Engineering Co., Ldt. K-NET and KiK-net records are available on the Internet. Fukuoka Prefecture and CTI Engineering records cannot be released to the public. Well logs were provided by CTI Engineering Co., Ldt.; they cannot be released to the public. Topographic map and cross sections were published in the Geological Survey Association of Kyushu, Fukuoka soil map, edited by the Editing Group of Fukuoka Soil Map. Generic Mapping Tools (http:// gmt.soest.hawaii.edu/, Wessel and Smith, 1995), Gnuplot (available at http://www.gnuplot.info/; updated October 2009), and MATLAB (available at http://www.mathworks. $\mathrm{com} /$ ) were used to plot the figures.

\section{Acknowledgments}

The authors are thankful to CTI Engineering Co., Ltd., for providing the borehole records. The earthquake records at K-NET and KiK-net stations are observed and placed on the web site by Natural Research Institute for 


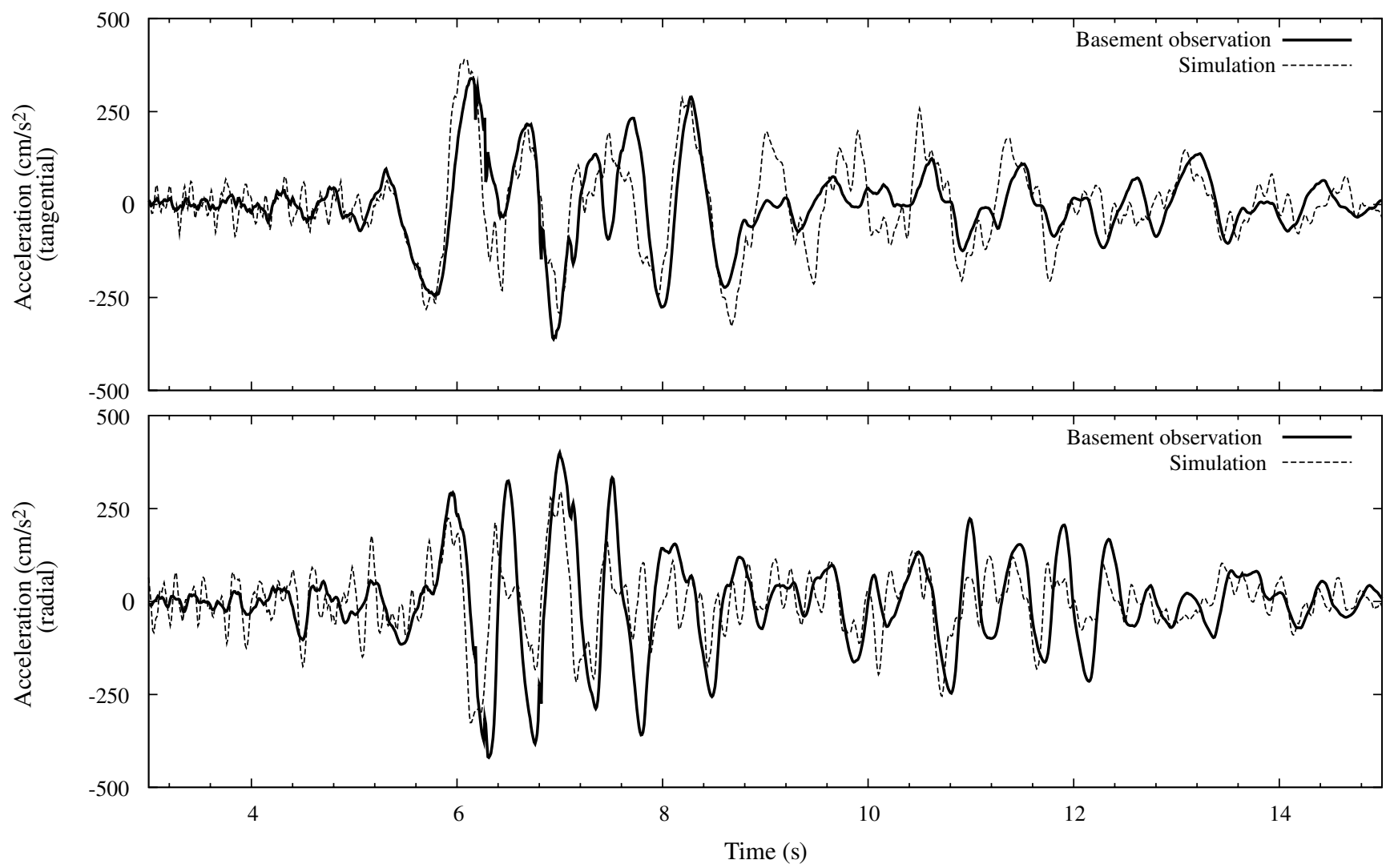

Figure 22. Comparison between observed (solid line) and simulated (dashed line) acceleration at the basement in transverse and radial directions.

\begin{tabular}{|c|c|c|c|c|c|c|c|c|c|c|c|c|}
\hline & F01 & & F02 & & F03 & & F04 & & F05 & & F06 & \\
\hline & 1.42 & & 3.56 & & 5.98 & & 7.54 & & 10.23 & & 12.08 & \\
\hline L01 & 1 & 0.00 & + & 0.06 & + & 0.22 & $千$ & 0.39 & 1 & 0.50 & 1 & 0.61 \\
\hline L02 & 1 & 0.00 & + & 0.20 & 1 & 0.78 & 1 & 0.78 & 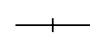 & 0.46 & 1 & 0.33 \\
\hline L03 & $t$ & 0.02 & + & 0.20 & + & 0.24 & + & 0.12 & 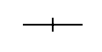 & 0.37 & 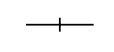 & 0.42 \\
\hline L04 & + & 0.07 & + & 0.24 & + & 0.09 & + & 0.30 & 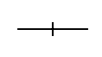 & 0.43 & 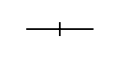 & 0.41 \\
\hline L05 & + & 0.05 & t & 0.03 & + & 0.18 & + & 0.05 & 1 & 0.42 & + & 0.13 \\
\hline L06 & + & 0.13 & 1 & 0.00 & 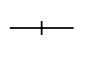 & 0.39 & + & 0.26 & 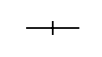 & 0.33 & 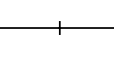 & 0.78 \\
\hline L07 & + & 0.10 & । & 0.00 & + & 0.20 & 1 & 0.29 & + & 0.05 & 1 & 0.29 \\
\hline L08 & + & 0.13 & + & 0.07 & + & 0.13 & 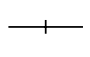 & 0.46 & 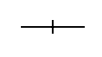 & 0.39 & + & 0.07 \\
\hline L09 & + & 0.05 & + & 0.05 & 1 & 0.00 & + & 0.10 & + & 0.34 & + & 0.24 \\
\hline L10 & + & 0.10 & + & 0.15 & + & 0.05 & + & 0.05 & 1 & 0.49 & 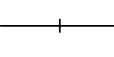 & 0.73 \\
\hline L11 & + & 0.05 & + & 0.10 & + & 0.14 & + & 0.10 & + & 0.08 & + & 0.12 \\
\hline L12 & + & 0.13 & + & 0.13 & + & 0.26 & + & 0.26 & + & 0.26 & + & 0.26 \\
\hline L13 & + & 0.07 & + & 0.13 & + & 0.26 & 1 & 0.33 & $千$ & 0.39 & 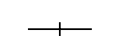 & 0.39 \\
\hline
\end{tabular}

Figure 23. Variation table of theoretical resonant frequencies with respect to $S$-wave velocity of a soil layer computed for a vertically incident $S$ wave using the velocity logging. Fxx denotes a resonant frequency, and Lyy denotes a layer (corresponding to Table 3). Float numbers below Fxx indicate the value of the resonant frequency Fxx. Vertical lines indicate the original location of a resonant frequency Fxx; horizontal lines located on the left- and right-hand side of vertical lines quantitatively represent the amount of shift of the frequency Fxx normalized by the height of the layer Lyy with respect to the decrease or increase of the $S$-wave velocity of the soil layer Lyy (float numbers indicate this amount of shift). Factors used to decrease or increase the $S$-wave velocity of a soil layer are 0.8 and 1.2 , respectively. 
(a)

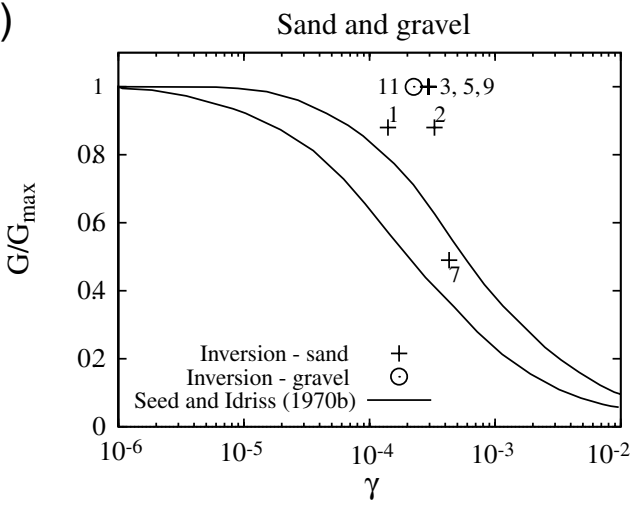

(b)

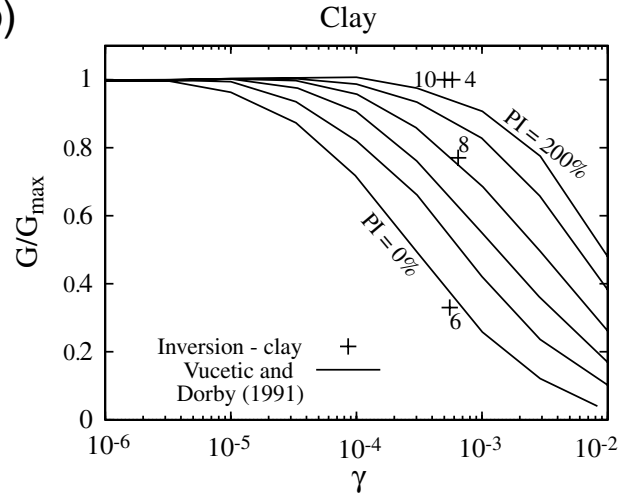

Figure 24. (a) Comparison of the strain-dependent characteristics inverted for sand and gravel layers with laboratory test results for sand (Seed and Idriss, 1970b) whose effective vertical stress ranges from 0.05 to $0.5 \mathrm{MPa}$. (b) Comparison of the strain-dependent characteristics inverted for clay layers with laboratory test results for clay (Vucetic and Dobry, 1991) whose plasticity index (PI) ranges from 0\% to $200 \%$. For both panel, numbers indicate layers of Table 3 .

Earth Science and Disaster Prevention (NIED). This work was performed while one of the authors (F. D. M.) was a visiting scholar at the Disaster Prevention Research Institute, Kyoto, on leave from Bureau de Recherches Géologiques et Minières, Orléans. This work was supported by the CARNOT Institute and the 21st Century COE Program of Kyushu University (H-14). Drs. S. Parolai, T. Satoh, and an anonymous reviewer made valuable suggestions to improve this article.

\section{References}

Aguirre, J., and K. Irikura (1997). Nonlinearity, liquefaction, and velocity variation of soft soil layers in Port Island, Kobe, during the Hyogo-ken Nanbu earthquake, Bull. Seismol. Soc. Am. 87, 1244-1258.

Aki, K. (1993). Local site effects on weak and strong ground motion, Tectonophysics 218, 93-111.

Aki, K. (2003). A perspective on the history of strong motion seismology, Phys. Earth Planet. In. 137, 5-11.

Archuleta, R. J., S. H. Seale, P. V. Sangas, L. M. Baker, and S. T. Swain (1992). Garner Valley downhole array of accelerometers: Instrumentation and preliminary data analysis, Bull. Seismol. Soc. Am. 82, 15921621.

Archuleta, R. J., S. H. Seale, P. V. Sangas, L. M. Baker, and S. T. Swain (1993). Garner valley downhole array of accelerometers: Instrumentation and preliminary data analysis, Bull. Seismol. Soc. Am. 83, 2039.

Asano, K., and T. Iwata (2006). Source process and near-source ground motions of the 2005 West Off Fukuoka Prefecture earthquake, Earth Planets Space 58, 93-98.

Assimaki, D., and J. Steidl (2007). Inverse analysis of weak and strong motion downhole array data from the Mw 7.0 Sanriku-Minami earthquake, Soil Dynam. Earthq. Eng. 27, 73-92.

Bard, P. Y., M. Campillo, F. J. Chavez-Garcia, and F. Sanchez-Sesma (1988). The Mexico earthquake of September 19, 1985-A theoretical investigation of large- and small-scale amplification effects in the Mexico City Valley, Earthq. Spectra 4, 609-633.

Beresnev, I. A., K.-L. Wen, and Y. T. Yeh (1995). Seismological evidence for nonlinear elastic ground behavior during large earthquakes, Soil Dynam. Earthq. Eng. 14, 103-114.

Bonilla, L. F., R. J. Archuleta, and D. Lavallee (2005). Hysteretic and dilatant behavior of cohesionless soils and their effects on nonlinear site response: Field data observations and modeling, Bull. Seismol. Soc. Am. 95, 2373-2395.

Bonilla, L. F., J. H. Steidl, J.-C. Gariel, and R. J. Archuleta (2002). Borehole response studies at the Garner Valley Downhole Array, Southern California, Bull. Seismol. Soc. Am. 92, 3165-3179.

Chang, C. Y., C. M. Mok, M. S. Power, Y. K. Tang, H. T. Tang, and J. C. Stepp (1991). Development of shear modulus reduction curves based on Lotung downhole ground motion data, in Proc. of the 2nd Int. Conf. on Recent Advances in Geotechnical Earthquake Engineering and Soil Dynamics, St. Louis, Missouri, 11-15 March 1991, 111-118.

Chávez-García, F. J., and D. Raptakis (2008). Inversion of soil structure and analysis of the seismic wavefield from a vertical array, in Proc. of the 14th World Conf. on Earthquake Engineering, Beijing, China, 12-17 October 2008.

Chin, B.-H., and K. Aki (1991). Simultaneous study of the source, path, and site effects on strong ground motion during the 1989 Loma Prieta earthquake: A preliminary result on pervasive nonlinear site effects, Bull. Seismol. Soc. Am. 81, 1859-1884.

Cramer, C., and C. Real (1992). A statistical analysis of submitted siteeffects predictions for the weak-motion blind prediction test conducted at the Turkey Flat, USA, site effects test area near Parkfield, California, in Proc. of the Int. Symp. on the Effects of Surface Geology on Seismic Motion, Odawara City, Japan, Volume 2, 15-20.

Cultrera, G. C., D. M. Boore, W. B. Joyner, and C. M. Dietel (1999). Nonlinear soil response in the vicinity of the Van Norman Complex following the 1994 Northridge, California, earthquake, Bull. Seismol. Soc. Am. 89, 1214-1231.

Darragh, R. B., and A. F. Shakal (1991). The site response of two rock and soil station pairs to strong and weak ground motion, Bull. Seismol. Soc. Am. 81, 1885-1899.

Field, E. H., P. A. Johnson, I. A. Beresnev, and Y. Zeng (1997). Nonlinear ground-motion amplification by sediments during the 1994 Northridge earthquake, Nature 390, 599-602.

Frankel, A. (1994). Dense array recordings in the San Bernardino Valley of Landers-Big Bear aftershocks: Basin surface waves, Moho reflections, and three-dimensional simulations, Bull. Seismol. Soc. Am. 84, 613624.

Frankel, A. D., D. L. Carver, and R. A. Williams (2002). Nonlinear and linear site response and basin effects in Seattle for the $M 6.8$ Nisqually, Washington, earthquake, Bull. Seismol. Soc. Am. 92, 2090-2109.

Ghayamghamain, M. R., and H. Kawakami (1996). On the characteristics of non-linear soil response and dynamic soil properties using vertical array data in Japan, Earthq. Eng. Struct. Dynam. 25, 857-870.

Goldberg, D. E. (1989). Genetic Algorithms in Search, Optimization, and Machine Learning, Addison-Wesley, Reading, Massachusetts, 432 pp.

Graves, R. (1993). Modeling three-dimensional site response effects in the Marina District Basin, San Francisco, California, Bull. Seismol. Soc. Am. 83, 1042-1063.

Haskell, N. A. (1953). The dispersion of surface waves in multilayered media, Bull. Seismol. Soc. Am. 43, 17-34.

Kawase, H., and K. Aki (1989). A study on the response of a soft basin for incident $S, P$, and Rayleigh waves with special reference to the long 
duration observed in Mexico City, Bull. Seismol. Soc. Am. 79, 13611382.

Kawase, H., and K. Aki (1990). Topography effect at the critical $S V$-wave incidence: Possible explanation of damage pattern by the Whittier Narrows, California, earthquake of 1 October 1987, Bull. Seismol. Soc. Am. 80, 1-22.

Kawase, H., and S. Matsushima (1998). Strong motion simulation in Kobe during the Hyogo-ken Nanbu earthquake of 1995 based on a threedimensional basin structure, J. Struct. Constr. Eng. Trans. Archit. Inst. 514, 111-118 (in Japanese with English abstract).

Kawase, H., and T. Sato (1992). Simulation analysis of strong motions in Ashigara Valley considering one- and two-dimensional geological structures, J. Phys. Earth 40, 27-56.

Kawase, H., T. Satoh, and K. Fukutake (1996). Simulation of the borehole records observed at the Port Island in Kobe, Japan, during the Hyogoken Nanbu earthquake of 1995, CD-ROM Ref. No. 140., in Proc. of the 11th World Conf. on Earthquake Engineering, Acapulco, Mexico, 23-28 June 1996, 8 pp.

Kawase, H., T. Satoh, and N. Umeda (2006). Strong motion characteristics observed during the West off Fukuoka earthquake of 2005 and their simulation, no. 53., in Proc. of Third Int. Symp. on the Effects of Surface Geology on Seismic Motion, Grenoble, France, 30 August1 September 2006, 587-597.

Kokusho, T. (2004). Nonlinear site response and strain-dependent soil properties, Curr. Sci. 87, 1363-1369.

Kwok, A. O. L., J. P. Stewart, and Y. M. A. Hashash (2008). Nonlinear ground-response analysis of Turkey Flat shallow stiff-soil site to strong ground motion, Bull. Seismol. Soc. Am. 98, 331-343.

Mazda, T., T. Irie, A. Sumaya, and H. Matsumoto (2005). Damage of building structures and their earthquake response at West off Fukuoka Prefecture earthquake, paper no. 0223, in Proc. 28th JSCE Earthquake Engineering Symposium, Japan Society of Civil Engineers (JSCE), Japan, Vol. 28, 1-8 (in Japanese with English abstract). Available at http:// www.jsce.or.jp/library/open/proc/maglist2/00578/2005/mg03.htm.

Mirodikawa, S. (1992). A statistical analysis of submitted predictions for the Ashigara Valley blind prediction test, in Proc. of Third Int. Symp. on the Effects of Surface Geology on Seismic Motion, Odawara City, Japan, Volume 2, 65-77.

Pavlenko, O. V., and K. Irikura (2003). Estimation of nonlinear timedependent soil behavior in strong ground motion based on vertical array data, Pure Appl. Geophys. 160, 2365-2379.

Pavlenko, O. V., and K. Irikura (2005). Identification of the non-linear behaviour of liquefied and non-liquefied soils during the 1995 Kobe earthquake, Geophys. J. Int. 160, 539-553.

Pavlenko, O. V., and K. Irikura (2006). Nonlinear behavior of soils revealed from the records of the 2000 Tottori, Japan, earthquake at stations of the Digital Strong-Motion Network KiK-net, Bull. Seismol. Soc. Am. 96, 2131-2145.

Satoh, T., and H. Kawase (2005). Simulation of strong motions in Fukuoka City during the 2005 West off Fukuoka Prefecture earthquake with special reference to thick Quaternary sediments around the Kego fault, Earth Planets Space 58, 105-110.

Satoh, T., M. Fushimi, and Y. Tatsumi (2001). Inversion of strain-dependent nonlinear characteristics of soils using weak and strong motions observed by borehole sites in Japan, Bull. Seismol. Soc. Am. 91, 365-380.

Satoh, T., M. Horike, Y. Takeuchi, T. Uetake, and H. Suzuki (1997). Nonlinear behavior of scoria evaluated from borehole records in eastern Shizuoka prefecture, Japan, Earthq. Eng. Struct. Dynam. 26, 781-795.

Satoh, T., H. Kawase, and T. Sato (1995). Evaluation of local site effects and their removal from borehole records observed in the Sendai region, Japan, Bull. Seismol. Soc. Am. 85, 1770-1789.

Seed, H. B., and I. M. Idriss (1970a). Analyses of ground motions at Union Bay, Seattle, during earthquakes and distant nuclear blasts, Bull. Seismol. Soc. Am. 60, 125-136.

Seed, H. B., and I. M. Idriss (1970b). Soil moduli and damping factors for dynamic response analyses, Technical Report No. EERC 70-10, University of California, Berkeley.

Shibuya, T., H. Kawase, and T. Seike (2009). Research on presumption of lying active behind fault that uses $\mathrm{H} / \mathrm{V}$ spectrum ratio by microtremor measurement-the Kego fault as an example, Bull. Jpn. Geol. Surv. (in Japanese).

Su, F., J. G. Anderson, and Y. Zeng (1998). Study of weak and strong ground motion including nonlinearity from the Northridge, California, earthquake, Bull. Seismol. Soc. Am. 88, 1411-1425.

Takizawa, H. (1982). Work done by earthquake ground shaking upon various types of dynamics systems, in Proc. of 6th Japan Earthquake Engineering Symposium, Tokyo, Japan, 1-3 December 1982, 10651072.

Thomson, W. (1950). Transmission of elastic waves through a stratified solid, J. Appl. Phys. 21, 89-93.

Vucetic, M., and R. Dobry (1991). Effect of soil plasticity on cyclic response, J. Geotech. Eng. 117, 89-107.

Wen, K. L. (1994). Non-linear soil response in ground motions, Earthq. Eng. Struct. Dynam. 23, 599-608.

Wessel, P., and W. H. F. Smith (1995). New version of the generic mapping tools released. EOS Trans AGU 76, 329.

Yamanaka, H., and H. Ishida (1996). Application of genetic algorithms to an inversion of surface-wave dispersion data, Bull. Seismol. Soc. Am. 86, 436-444.

Zeghal, M., A.-W. Elgamal, H. T. Tang, and J. C. Stepp (1995). Lotung downhole array. II: Evaluation of soil nonlinear properties, J. Geotech. Eng. 121, 363-378.

Bureau de Recherches Géologiques et Minières (BRGM)

Natural Risks and Security of $\mathrm{CO}_{2}$ Storage Division

3 Avenue C. Guillemin

BP 36009,45060

Orléans Cedex 2, France

(F.D.)

Disaster Prevention Research Institute

Kyoto University Gokasho

Uji, 611-0011 Japan

(H.K.)

Laboratoire Mécanique des Sols

Structures et Matériaux CNRS UMR 8579

Ecole Centrale de Paris

Chatenay-Malabry, France

(A.M.)

Manuscript received 25 May 2009 